\title{
G-CSF SECRETED BY EPIGENETICALLY REPROGRAMMED MUTANT IDH1 \\ GLIOMA STEM CELLS REVERSES THE MYELOID CELLS'-MEDIATED IMMUNOSUPPRESSIVE TUMOR MICROENVIRONMENT
}

\author{
Mahmoud S Alghamri ${ }^{1,2}$, Ruthvik P Avvari ${ }^{1,2}$, Rohit Thalla ${ }^{1,2}$, Neha Kamran ${ }^{1,2}$, Li Zhang ${ }^{1,2}$, \\ Maria Ventosa $^{1,2}$, Ayman Taher ${ }^{1,2}$, Syed Mohd Faisal ${ }^{1,2}$, Felipe J. Núñez ${ }^{1,2 \dagger}$, María Belén Garcia- \\ Fabiani $^{1,2}$, Santiago Haase ${ }^{1,2}$, Stephen Carney $^{1,2}$, Daniel Orringer ${ }^{1 \#}$, Shawn Hervey-Jumper ${ }^{3}$, \\ Jason Heth ${ }^{1}$, Parag G Patil ${ }^{1}$, Wajd N Al-Holou ${ }^{1}$, Karen Eddy ${ }^{1}$, Sophia Merajver ${ }^{4}$, Peter J Ulintz ${ }^{4}$, \\ Joshua Welch $^{5}$, Chao Gao ${ }^{5}$, Jialin Liu ${ }^{5}$, Gabriel Núñez ${ }^{6}$, Dolores Hambardzumyan ${ }^{7}$, Pedro R \\ Lowenstein $^{1,2,8}$ and Maria G Castro ${ }^{1,2,8^{*}}$ \\ ${ }^{1}$ Department of Neurosurgery, University of Michigan Medical School, Arbor, MI 48109, USA. \\ ${ }^{2}$ Department of Cell and Developmental Biology, University of Michigan Medical School, Ann \\ Arbor, MI 48109, USA. \\ ${ }^{3}$ Department of Neurosurgery, University of California San Francisco, USA. \\ ${ }^{4}$ Department of Internal Medicine, University of Michigan Medical School, Ann Arbor, MI \\ 48109, USA. \\ ${ }^{5}$ Department of Computational Medicine and Bioinformatics, University of Michigan Medical \\ School Ann Arbor, MI 48109, USA \\ ${ }^{6}$ Department of Pathology, University of Michigan Medical School, Ann Arbor, MI 48109, USA \\ ${ }^{7}$ Department of Oncological Sciences, The Tisch Cancer Institute and Department of \\ Neurosurgery, Mount Sinai Icahn School of Medicine, New York, NY, USA
}


${ }^{8}$ Rogel Cancer Center, University of Michigan, Ann Arbor, MI 48109, USA

${ }^{\text {\# }}$ Current address: Department of Neurosurgery, New York University, New York, NY, USA

${ }^{\dagger}$ Current Address: Leloir Institute Foundation, Buenos Aires, Argentina

RUNNING TITLE: Reprogramming the $m I D H 1$ glioma immune microenvironment

KEYWORDS: Glioma, tumor microenvironment, immunosuppression, G-CSF, myeloidderived suppressor cells, sc-RNA seq

FINANCIAL SUPPORT: This work was supported by "National Institutes of Health/National Institute of Neurological Disorders \& Stroke (NIH/NINDS) Grants [R37-NS094804, R01NS105556, R21-NS107894 and Rogel Cancer Center Scholar Award to M.G.C.]; NIH/NINDS Grants [R01-NS076991, R01-NS082311, and R01-NS096756 to P.R.L.]; the Department of Neurosurgery; the Pediatric Brain Tumor Foundation, Leah's Happy Hearts Foundation, Chad Tough Foundation, Pediatric Brain Tumor Foundation, and Smiles for Sophie Forever Foundation to [M.G.C. and P.R.L]. NIH/NCI T32- CA009676 Post-Doctoral Fellowship to M.S.A and American Brain Tumor Association Basic Research Fellowship 'in Memory of Bruce and Brian Jackson' to M.B.G.F.

*CORRESPONDENCE: Maria G Castro, Room 4570C, MSRB II, 1150 West Medical Center Drive, Michigan Medicine, Ann Arbor, MI 48109 e-mail: mariacas@umich.edu

CONFLICT OF INTEREST: Authors declare no conflict of interest

Total Words Count: 19,884

Number of Figures: 7 


\begin{abstract}
Mutation in isocitrate dehydrogenase $(m I D H)$ is a gain of function mutation resulting in the production of the oncometabolite, R-2-hydroxyglutarate, that inhibits DNA and histone demethylases. The resultant hypermethylation phenotype reprograms the glioma cells' transcriptome and elicits profound effects on glioma immunity. We report that in mouse models and human gliomas, $m I D H 1$ in the context of ATRX and TP53 inactivation results in global expansion of the granulocytic myeloid cells' compartment. Single-cell RNA-sequencing coupled with mass cytometry analysis revealed that these granulocytes are mainly nonimmunosuppressive neutrophils and pre-neutrophils; with a small fraction of polymorphonuclear myeloid-derived suppressor cells. The mechanism of $m I D H 1$ mediated pre-neutrophils expansion involves epigenetic reprogramming which leads to enhanced expression of the granulocyte colony-stimulating factor (G-CSF). Blocking G-CSF restored the inhibitory potential of PMNMDSCs and enhanced tumor progression. Thus, G-CSF induces remodeling of the inhibitory PMN-MDSCs in $m I D H 1$ glioma rendering them non-immunosuppressive; and having significant therapeutic implications.
\end{abstract}




\section{SIGNIFICANCE}

$m I D H 1$ is the most common mutation in gliomas associated with improved prognosis. Gliomas harboring $m I D H 1$, together with $A T R X$ and TP53 inactivation, exhibit higher circulating levels of G-CSF, ensuing the recruitment and expansion of non-suppressive neutrophils, pre-neutrophils and small fraction of PMN-MDSCs to the TME leading to an immune permissive phenotype. 


\section{INTRODUCTION}

Mutation in isocitrate dehydrogenase $(m I D H)$ is a common genetic lesion occurring in adult glioma patients (1). Approximately $90 \%$ of $I D H 1$ mutations occur in exon 4 at codon 132 , resulting in a change of a single amino acid from arginine to histidine (R132H). Less common IDH2 mutations occur in an analogous codon at position R172 (2). Although IDH1/2 mutations are always heterozygous, they exert a dominant gain of function enzymatic activity which leads to the production of 2-hydroxyglutarate (2HG). Excessive $2 \mathrm{HG}$ production causes DNA hypermethylation via inhibition of methylcytosine dioxygenase TET2 $(3,4)$, and also promotes histone hypermethylation through competitive inhibition of $\alpha$-ketoglutarate $(\alpha \mathrm{KG})$ dependent Jumonji-C histone demethylases $(5,6)$. This leads to epigenetic reprogramming of gene expression within the $m I D H 1$ glioma cells $(5,7,8)$.

The IDH1 mutation plays an important role in glioma development and progression, by modulating tumor cells' intrinsic mechanisms and also by remodeling the tumor microenvironment. Metabolically, IDH1 is one of the enzymes that encodes an irreversible reaction in the tricyclic acid cycle. Disruption of the IDH reaction results in defective mitochondrial oxidative phosphorylation, glutamine metabolism, lipogenesis, glucose sensing, and altering cellular redox status (9-14). Mutation in $I D H 1$ also inhibits glioma stem cell differentiation $(5,13)$, upregulates vascular endothelial growth factor $(15,16)$, and produces high levels of hypoxia-inducible factor-1 $\alpha$, all of which promote glioma invasion $(14,17,18)$. We have recently shown that $m I D H 1$ when expressed concomitantly with $A T R X$ and TP53 inactivation, results in enhanced DNA damage response, leading to radio-resistance in mouse and human glioma cells in vitro and extending the median survival (MS) in a genetically engineered mouse 
glioma model (19). Nevertheless, the molecular mechanisms that mediate enhanced survival in patients with $m I D H 1$ glioma remain elusive. We hypothesize that epigenetic-mediated mechanisms could be an important contributing factor modulating the immune microenvironment

The success of immunotherapeutic approaches in several non-central nervous system (CNS) cancers has driven the evaluation of numerous immune-mediated therapeutic strategies in glioma clinical trials (20). To date, Immune checkpoint blockade used as a monotherapy in combination with standard of care did not demonstrate survival benefits in glioma patients (2123). The lack of therapeutic efficacy of immunotherapies in the clinical arena, can be attributed in part, to the immunosuppressive properties elicited by glioma infiltrating immune cells (22-24). Myeloid-derived suppressor cells (MDSCs) have emerged as one of the dominant immunosuppressive cells that directly interfere with the efficacy of immunotherapy (25-27). In glioma patients, it has been demonstrated that granulocytic-MDSCs (also known as PMNMDSCs) are a major subset that expands during glioma progression which negatively correlates with patient's survival (28-30). We have recently shown that depletion of MDSCs in wild-type IDH1 glioma-bearing mice markedly enhanced the efficacy of an immune stimulatory/conditional cytotoxic gene therapy (25); highlighting the role of MDSCs in hampering anti-glioma immunity.

Several studies suggested that $m I D H 1$ may play a critical role in shaping the immunological landscape of the tumor microenvironment (31-34). Glioma samples from patients with $m I D H 1$ have decreased PD-L1 expression (due to hypermethylation of the CD274 promoter) (32), 
reduced level of inflammation, and reduced levels of infiltrating immune cells $(31,33,35)$.

Myeloid cells represent the major immune cells in glioma TME $(25,36,37)$. It has been shown that $\mathrm{mIDH} 1$ glioma with mixed genetic background (PDGFB/shP53/Ink4a/Arf $\left.{ }^{/-} / \mathrm{mIDH1}\right)$ exhibit fewer tumor-infiltrating macrophages, dendritic cells (DCs), and neutrophils, compared to the wild-type $I D H 1$ counterparts (31). Nevertheless, the impact of $m I D H 1$ on tumor-infiltrating myeloid cells' phenotype and function have not been explored; particularly in the context of concurrent inactivation mutation in ATRX and TP53 $(1,38)$.

Granulocytes are the major population within the bone marrow (BM) myeloid cells' compartment, which differentiate under steady-state conditions into neutrophils. Under physiological conditions, these cells have emerged as major contributors to protection against pathogens and are important mediators of tissue remodeling $(39,40)$. However, during inflammation and cancer, the activation of various signaling pathways, such as Jak-Stat, and MAPK pathways, results in rapid mobilization of granulocytes and neutrophils from the BM, favoring the generation of immunosuppressive PMN-MDSCs (41-43). These cells share the same origin (granulocyte-macrophage progenitors (GMPs)) and differentiation pathways, yet, PMNMDSCs have distinct genomic and biochemical features and are immunosuppressive $(44,45)$. Therefore, it became critical to incorporate both transcriptomic analysis at the single-cell level (single-cell RNA sequencing) as well as functional characterization to uncover the immunosuppressive tumor-infiltrating PMN-MDSCs in glioma.

We report that in genetically engineered mouse glioma models, $I D H 1$ mutation, in the context of ATRX and TP53 deficiency, caused an expansion of tumor-infiltrating granulocytes. 
Upon phenotypic and functional characterization, we uncovered that granulocytes in $m I D H 1$ glioma, counter to the granulocytes infiltrated in wtIDH1, did not exhibit immune-suppressive properties. Single-cell sequencing coupled with mass cytometry analysis revealed that these granulocytes are heterogeneous and composed of neutrophils and pre-neutrophils, with a smaller proportion of bona fide immunosuppressive PMN-MDSCs. Moreover, primary human gliomas showed a higher frequency of cells exhibiting the PMN-MDSCs gene signature in wtIDHI tumors when compared to $m I D H 1$ glioma. Our data demonstrate that the mechanism by which mIDH1 in glioma mediates the expansion of non-immune suppressive granulocytes involves epigenetic reprogramming. This leads to enhanced expression of granulocyte colony-stimulating factor (G-CSF) by stem-like $m I D H 1$ glioma cells. Blocking G-CSF restored the inhibitory potential of PMN-MDSCs and substantially enhanced tumor progression, whereas recombinant G-CSF administration, prolonged the MS of wtIDH1 glioma bearing mice. Consistent with that, LGG-astrocytoma with $m I D H 1$ is the sole tumor cohort within all TCGA data sets in which high CSF3 gene expression correlates with favorable patients' outcome. Our work provides a new insight of the impact of $m I D H 1$ on the phenotypic and functional properties of myeloid cells in the glioma TME. 


\section{MATERIALS AND METHODS}

Study design: To study the impact of glioma $I D H 1^{R 123 H}$ on myeloid cell phenotype and function, we generated a genetically engineered animal model injecting SB plasmids encoding NRA $\mathrm{G} 12 \mathrm{~V}, \operatorname{sh} A T R X$ and $\operatorname{shp} 53$ with or without $I D H 1^{R 132 H}$ (wtIDH1 and $m I D H 1$ respectively) into the lateral ventricle of neonatal mice (46-48). Sample size and any data inclusion/exclusion were defined individually for each experiment. We also used an animal model generated by intracranial implantation of glioma NS (wtIDH1 and $m I D H 1)$ derived from our genetically engineered animal model (46,49). Additionally, we used an alternative model (PDGFB/shP53/shATRX/Ink4a/Arf ${ }^{--} w t I D H 1-N S$ or $\left.m I D H 1-N S\right)$ that does not encode RASactivating mutations. We performed pan characterization of all immune cells by flow cytometry and mass cytometry and identified each immune cell population using unique biomarkers. Detailed information regarding the source of antibodies and immune cells' gating are listed in supplementary tables S1, S2, and S3. We also performed scRNA-seq to define the PMN-MDSCs cell population in both mouse and human glioma tissue derived from patients harboring $I D H 1^{R 132 H}$ or $w t I D H 1$. We validated PMN-MDSCs by functional analysis of T-cell's inhibitory characteristics. The numbers of replicates are reported in the figure legends. All scRNA-seq data were deposited in public databases as is indicated in the respective sections. Materials and Methods are described in detail in the Supplementary Materials section.

Statistical analysis: Sample sizes were selected based on preliminary data from pilot experiments and previously published results in the literature and our laboratory. Unpaired Student t-test or one-way analysis of variance (ANOVA), followed by Tukey's multiple comparisons post-test were utilized for comparing experimental groups with controls from flow 
cytometry analysis, cytokine analysis, mass cytometry analysis, and T-cell functional assays. RNA-seq, data were processed using the Tuxedo Suite, and differentially expressed genes were considered when FDR $\leq 0.05$, and fold change $\geq \pm 1.5$. All single-cell sequencing data were processed by Cell Ranger Pipeline version 3.1.0. Filtered digital gene expression matrix files (DGE) matrices containing the number of unique molecular identifiers (UMI) counts per gene per cell were analyzed using the Seurat $\mathrm{R}$ package version 3.1.4. Statistically significant principal components were determined using the jackstraw function $(50,51)$. All quantitative data are presented as the Means \pm SEM from at least three independent samples. ANOVA and twosample t-tests were used to compare continuous outcomes between groups. Survival curves were analyzed using the Kaplan-Meier method and compared using Mantel-Cox tests; the effect size is expressed as MS. Differences were considered significant if $P<0.05$. All analyses were conducted using GraphPad Prism software (version 8.00), or R (version 3.4). The statistical tests used are indicated in each figure legend. 


\section{RESULTS}

\section{mIDH1 glioma causes a systemic increase in polymorphonuclear (PMN) myeloid cells}

The role of $I D H 1$ mutation in shaping the immune landscape of glioma remains unexplained. We generated a $m I D H 1$ genetically engineered mouse model (GEMM) of glioma using the Sleeping Beauty (SB) transposon system $(46,52,53)$ to uncover the impact of $I D H 1^{R 132 H}$ in the context of ATRX and TP53 deficiency on glioma infiltrating immune cells (Fig. 1A). Two groups of tumors were generated using the SB method, each contains a combination of genetic lesions commonly encountered in astrocytoma; mIDH1 (NRASG12V+shp53+shATRX+mIDH1 $\left.{ }^{R 132 H}\right)$

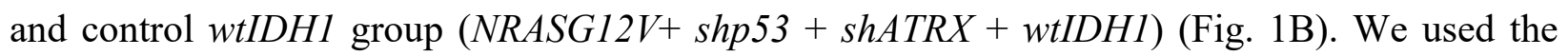
merit of mass cytometry (CyTOF) (Supplementary Table S1) which measures 37 parameters simultaneously to analyze immune cell composition within the TME from each group. Using SPADE analysis, we found that glioma TME contains several immune cell types including macrophages, dendritic cells (DCs), B-cells, NK cells, $\mathrm{CD}^{+}$T-cells, and $\mathrm{CD}^{+}$T-cells (Fig. 1C, D). Moreover, there was an expansion of cells (depicted by the large red/yellow nodes) characteristic for myeloid-derived suppressor cells $\left(\mathrm{CD} 45^{\mathrm{high}} / \mathrm{CD} 11 \mathrm{~b}^{+} / \mathrm{Gr}-1^{+}\right)$in the TME of $m I D H 1$ glioma compared to $w t I D H 1$ glioma (Fig. 1C, D). Similarly, visual inspection of viSNE plots, which represent high-dimensional CyTOF output in two dimensions (54), showed a higher percentage of $\mathrm{Gr}-1^{+}$cells in the TME from $m I D H 1$ glioma compared to those from wtIDH1 glioma (Fig. 1C, D; insets). We confirmed that this difference is statistically significant using a $\chi^{2}$ test $(p<0.0001)$. The Gr-1 antibody can detect both the granulocytic

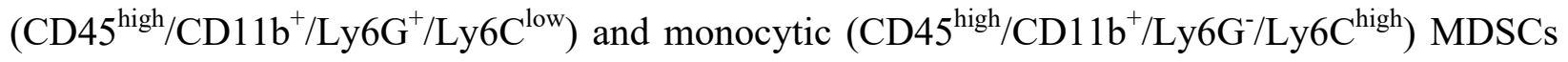
population. We found that the majority of the expanded myeloid cells in $m I D H 1$ tumor belonged to the granulocytic population, with no changes in the frequency of the monocytic population 
(Supplementary Fig S1A). In addition to the increase in granulocytes, $m I D H 1$ tumors showed a decreased frequency of macrophages $(2.7$ fold) and dendritic cells ((DCs) $\sim 4$ fold) with no significant change in the frequency of lymphocytes (including NK cells, B-cells, CD8 ${ }^{+}$and $\mathrm{CD} 4^{+}$ T-cells) as compared to wtIDH1 tumors (Supplementary Fig. S1B-G). Notably, there was no significant difference in the percentage of $\mathrm{CD} 45^{+}$cells between wtIDH1 and $m I D H 1$ glioma (Supplementary Fig. S1H). We generated neurospheres (NS) from mouse glioma subgroups (Fig 1B), and we used the implantable animal model to analyze the frequency of $\mathrm{CD} 45^{\text {high }} / \mathrm{CD} 11 \mathrm{~b}^{+} / \mathrm{Gr}-1^{+}$population at mid-stage (12 days after implantation) and at symptomatic stage of tumor development (Fig 1E, F). In both time points, we found that the mIDH1 tumor group had an increased number and percentage of $\mathrm{CD} 45^{\text {high }} / \mathrm{CD} 11 \mathrm{~b}^{+} / \mathrm{Gr}-1^{+}$cells compared to the wtIDH1 group (Mid-stage: $6.91 \pm 1.4 \%$ vs. $17.52 \pm 3.6 \%$, Symptomatic stage: $32.5 \pm 4.07 \%$ vs. $73.9 \pm 4.6 \%$ in $w t I D H 1$ vs $m I D H 1$; respectively, Fig. 1E, F; Supplementary Fig. S2A); the majority of these cells belong to granulocytic $\left(\right.$ Ly6G $\left.{ }^{+}\right)$origin (Fig. 1G). We validated our results using an animal model of $m I D H 1$ glioma independent of $R A S$ activating mutation $(36,55)$. Brain tumors were induced with replication-competent avian leukemia virus splice acceptor (RCAS) expressing platelet-derived growth factor $\beta(P D G F B)$, shP53, and $m I D H 1$ or $w t I D H 1$ in mixed background NTva_Ink4a/Arf ${ }^{-/}$mice. The neurospheres generated from these tumors were engineered to encode $\operatorname{shATRX}$ to generate glioma cells with the following molecular alterations: PDGFB/shP53/shATRX/Ink4a/Arf//mIDH1 or PDGFB/shP53/shATRX/Ink4a/Arff/wtIDH1 (46). Using this additional GEMM, we confirmed that $m I D H 1$ tumor-bearing animals exhibit an expanded $\mathrm{CD} 45^{\text {high }} / \mathrm{CD} 11 \mathrm{~b}^{+} / \mathrm{Gr}-1^{+}$population with a high predominance of $\mathrm{CD} 45^{\text {high }} / \mathrm{CD} 11 \mathrm{~b}^{+} / \mathrm{Ly}_{6 \mathrm{G}}^{+}$population ( 2-fold, $P<0.001$; Supplementary Fig. S2D, E). The expansion of $\mathrm{CD} 45^{\text {high }} / \mathrm{CD} 11 \mathrm{~b}^{+} / \mathrm{Gr}-1^{+}$cells was not limited to the tumor site; in both the 
circulation and the spleen of $m I D H 1$ tumor-bearing animals, there was a higher $(P<0.005)$ number and percentage of $\mathrm{CD} 45^{\mathrm{high}} / \mathrm{CD} 11 \mathrm{~b}^{+} / \mathrm{Gr}-1^{+}$(Blood; $17.65 \pm 2.3 \%$ vs. $50.05 \pm 4.4 \%$, spleen; $26.6 \pm 2.7$ vs. $66.8 \pm 5.4 \%$ in $w t I D H 1$ vs $m I D H 1$ tumor, respectively), the majority of which belong to granulocytic origin (Fig. 1H-M, Supplementary Fig. S2B, C). Similar to the $\mathrm{TME}$, in the circulation and spleen from tumor-bearing animals, there was no significant difference in the M-MDSCs between wtIDH1 and $m I D H 1$ glioma bearing mice. However, mIDH1 exhibited a decreased number of macrophages, with no differences in the DCs or lymphocytes (Supplementary Fig. S3, 4). Collectively, these results suggest that $m I D H 1$ tumor causes activation of pathways involved in granulocytic myeloid cells' expansion.

\section{mIDH1 glioma development results in profound remodeling of BM hematopoiesis}

The expansion of the granulocytic myeloid cells within the TME, blood, and spleen suggested that $\mathrm{mIDH} 1$ tumor growth induces profound alterations in the bone marrow (BM) hematopoiesis. Therefore, we examined the changes in hematopoiesis within the BM and spleen of the SBinduced murine glioma model. The absolute number and relative proportion of hematopoietic stem cells (HSCs) were decreased in the BM from $m I D H 1$ tumor-bearing mice $(2.2$-fold, $p<$ 0.05, Fig. 2A, B). In contrast, BM from $m I D H 1$ tumors contained higher numbers and frequencies of myeloid progenitors (MPs) $(\% \mathrm{MP} \sim 35 \%, p<0.05$, Fig. $2 \mathrm{C})$. In the spleen, there were no differences in the frequency of HSCs between the wtIDHI and mIDH1 tumor-bearing animals (Supplementary Fig. S5A, B). However, spleens from $m I D H 1$ tumor-bearing animals showed more than two-fold increase in MPs compared to wtIDH1 tumors $(P<0.05$, Supplementary Fig. S5A, C). There was also a higher frequency (2-fold) of granulocytemacrophage precursors (GMPs) in both the BM and spleen of $m I D H 1$ tumor-bearing animals $(P<0.05$, Fig. 2D, Supplementary Fig. S5D, F $)$. Despite the increase in MPs and GMPs, there 
was no significant change in the frequency of common lymphocyte progenitors (CLPs) between the two groups (Fig. 2E, Supplementary Fig. S5E, G). The increased production of granulocytes, MPs, and GMPs in BM and spleen supports the activation of the granulocytic myeloid differentiation pathway in the $m I D H 1$ tumor-bearing animals (Fig. 2F).

\section{Molecular and functional characterization of $\mathrm{mIDH} 1$ tumor-infiltrating granulocytes}

A hallmark of the glioma microenvironment is the accumulation of immunosuppressive immune cells, which in part is elicited by MDSCs infiltration in the tumor (25). Thus, we investigated the molecular and functional characteristics of the expanded $\mathrm{CD} 45^{\text {high }} / \mathrm{CD} 11 \mathrm{~b}^{+} / \mathrm{Ly}_{6 \mathrm{G}}{ }^{+}$in $m I D H 1$ tumors. First, we examined the surface expression of T-cell suppressive/co-stimulatory molecules commonly expressed by PMN-MDSCs in wtIDH1, and $m I D H 1$ tumors. Interestingly, in the $\mathrm{CD} 45^{\mathrm{high}} / \mathrm{CD} 11 \mathrm{~b}^{+} / \mathrm{Ly}_{6 \mathrm{G}}{ }^{+}$cells from $m I D H 1$ TME, the expression level of immunosuppressive as well as costimulatory molecules, such as PD-L1, CD86, CD80, IL-4R $\alpha$, iNOS, and Arginase1, was lower compared to the $\mathrm{Ly}_{6 \mathrm{G}}^{+}$cells from wtIDH1 TME (Fig. 2 H-M). In order to characterize the molecular differences between mIDH1 and wtIDH1 tumorinfiltrating $\mathrm{CD} 45^{\text {high }} / \mathrm{CD} 11 \mathrm{~b}^{+} / \mathrm{Gr}-1^{+}$, we purified these cells from tumor-bearing animals of these two groups, and performed transcriptome analysis. Granulocytes from $m I D H 1$ tumors have decreased expression of all immunosuppressive genes associated with the PMN-MDSCs signature, such as $I l 1 \beta, \operatorname{Arg} 1, T g f b 1, C D 274$, and Stat3 (Fig. 2G). Genes which mediate innate immunity, such as $\operatorname{tr} 2, \operatorname{tlr} 7$, and $\operatorname{tr} 8$, as well as antigen presentation and processing, were upregulated in granulocytes from mIDH1 TME (Supplementary Fig. S6A). To further investigate the functions of the differentially expressed genes, we performed gene set enrichment analysis (GSEA) (56). The most significantly enriched gene sets in the $m I D H 1$ group were related to the immune response (Supplementary Fig. 6B). Tlr7, tlr8, and $\operatorname{tlr} 13$ were upregulated, whereas 
genes important for monocyte differentiation (cebp- $\beta$, and $\operatorname{Irf8})$, as well as immunosuppressive genes in myeloid cells (Ill $\beta$, and Arg1), were downregulated (Supplementary Fig. 6B). Collectively, these results suggest that the expanded granulocytes in $m I D H 1$ tumor exhibit downregulation of immunosuppressive PMN-MDSCs gene signature.

Immunosuppressive PMN-MDSCs are characterized by their ability to suppress T cells' expansion, therefore we examined the influence of tumor-infiltrating CD $45^{\text {high }} / \mathrm{CD} 11 \mathrm{~b}^{+} / \mathrm{Ly}_{6 \mathrm{G}}{ }^{+}$ myeloid cells on antigen-specific T-cell proliferation. We isolated granulocytes by flow cytometry from gliomas expressing wtIDH1 or $m I D H 1$ and co-cultured them with carboxyfluorescein diacetate succinimidyl ester (CFSE)-labeled splenocytes from OT-1 mice (Fig. 2N). Isolated granulocytes were next stimulated with the cognate ova albumin peptide SIINFEKL (SIIN) to induce OT-1 splenocyte proliferation (Fig. 2N) (57). In response to SIIN, T-cells proliferation spiked to $\sim 90 \pm 4.9 \%$ in the control condition (T+SIIN) (Fig. 2 O, P). When $\mathrm{CD} 45^{\text {high }} / \mathrm{CD} 11 \mathrm{~b}^{+} / \mathrm{Ly} 6 \mathrm{G}^{+}$myeloid cells from the TME of $w t I D H 1$ tumors were added to the culture at different ratios $(1: 1,2: 1,4: 1)$, the percentage of proliferating T-cells was reduced to $\sim 48 \%, 64 \%$, and $75 \%$, respectively $(P<0.001$; Fig. $2 \mathrm{O}, \mathrm{P})$. Interestingly, $\mathrm{CD} 45^{\text {high }} / \mathrm{CD} 11 \mathrm{~b}^{+} / \mathrm{Ly} 6 \mathrm{G}^{+}$cells isolated from the TME of $m I D H 1$ gliomas did not suppress antigen-specific T-cell proliferation at any co-culturing ratio (Fig. 2O, P). Together, these results suggest that the granulocytes from the wtIDH1 tumor are inhibitory and thus can be defined as PMN-MDSCs, whereas the expanded granulocytes in $m I D H 1$ TME are not inhibitory and cannot be classified as PMN-MDSCs.

To further investigate the impact of $m I D H 1$ in the context of ATRX and TP53 inactivating mutations on the phenotype and function of $\mathrm{CD} 45^{\text {high }} / \mathrm{CD} 11 \mathrm{~b}^{+} / \mathrm{Ly} 6 \mathrm{G}^{+}$cells, we performed an $e x$ vivo MDSC differentiation assay. We isolated BM cells from WT animals and co-cultured them 
with wtIDH1, or $m I D H 1$ NS (2:1; BM cells: neurospheres; respectively) (Supplementary Fig. S7A). After seven days, we analyzed the frequency of granulocytes formed in each condition. Results showed that in the mIDH1 NS co-culture, there was a higher frequency of $\mathrm{CD} 45^{+} / \mathrm{CD} 11 \mathrm{~b}^{+} / \mathrm{Ly}_{6 \mathrm{G}}{ }^{+}$cells compared to those generated by co-cultures with $w$ tIDH1 NS (63.3 $\pm 2.1 \%$ vs. $85.3 \pm 1.5 \%$ for wtIDH1 vs. mIDH1, respectively, $\mathrm{p}<0.05$ Supplementary Fig. S7B). Granulocytes in the mIDH1 NS co-culture expressed lower levels of Arg1, PD-L1 and CD80 compared to those from wtIDH1 NS co-culture, (Supplementary Fig. S7C-E). The immunosuppressive property of the ex vivo-generated $\mathrm{CD}^{2} 5^{+} / \mathrm{CD} 11 \mathrm{~b}^{+} / \mathrm{Ly}_{6 \mathrm{G}}{ }^{+}$cells was investigated by in vitro suppression assays. Consistent with the in vivo experiments, $\mathrm{CD} 45^{+} / \mathrm{CD}_{11 \mathrm{~b}} / \mathrm{Ly}_{6 \mathrm{G}}{ }^{+}$cells generated by co-culturing with wtIDH1 NS (1:1) inhibit T-cell proliferation, whereas those generated from $m I D H 1$ NS were not inhibitory (Supplementary Fig. S7F, G). Collectively, these data validate that a tumor-derived factor is responsible for developing the non-immunosuppressive granulocytes in $m I D H 1$ glioma TME.

\section{Single-cell transcriptomes analysis reveals neutrophils and pre-neutrophils are the major granulocytic lineages in $\mathrm{mIDH} 1 \mathrm{TME}$}

Single-cell RNA-seq provides a powerful approach to dissect heterogeneous immune cells, by providing a transcriptome-wide profiling at the cellular level (58). We used this approach coupled with mass cytometry to compare the molecular differences of the TME-derived granulocytes on an individual cell basis (Fig. 3A). Two biological replicates of purified immune cells from TME of $m I D H 1$ mice $(8,881$ cells) and TME of wtIDH1 mice $(7,408$ cells) were sequenced at an average depth of $\sim 20,000$ reads per cell. After filtering cells with low overall expression and/or high mitochondrial gene expression, we performed dimensionality reduction and unsupervised cell clustering using methods implemented in the Seurat software suite 
independently for $m I D H 1$ and wtIDH1 datasets to identify distinct cell populations (51). In $m I D H 1$, we identified 14 distinct cell clusters expressing known markers of major immune cell types (Fig. 3B). Granulocytes formed the largest population and consisted of three clusters, which we refer to as C1, C2, and C3 (Fig. 3B; Supplementary Fig. S8B, D). C1 displayed high expression of PMN-MDSCs-related genes such as $\mathrm{Illb}$ and $\mathrm{Arg} 2$, two major immunosuppressive factors previously used to define PMN-MDSCs in cancer models $(59,60)$ (Fig. 3C; Supplementary Fig. S8B, D). C2 constitutes the largest granulocytic cluster, expressing high levels of $S 100 a 8$, inflammatory cytokines involved in the recruitment of $\mathrm{CD}^{+} \mathrm{T}$-cells $(\mathrm{Ccl} 3$, and Ccl4), and cell cycle genes such as (Cdc20, and G0s2) (Fig. 3B; Supplementary Fig. S8B, D) (61). C3 expressed genes involved in neutrophil maturation (Cebpe and Mpo; Fig. 3C, Supplementary Fig. S8B, D). These results suggested that $\mathrm{C} 1$ represents the true PMN-MDSCs population within the TME of $m I D H 1$ tumors, whereas $\mathrm{C} 2$ and $\mathrm{C} 3$ correspond to pre-neutrophils and neutrophils, respectively. Interestingly, in wtIDH1, there was only one cluster of granulocytes (C7; Supplementary Fig. S8A, C). This cluster expressed PMN-MDSC related genes such as Illb and Arg2, similar to cluster C1 in TME-mIDH1 (Supplementary Fig. S8A, C). To confirm that granulocytes in wtIDH1 tumor (C7) are similar to $\mathrm{C} 1$ granulocytes in the $m I D H 1$ tumor, we integrated the wtIDH1 and $m I D H 1$ tumor-infiltrating immune cell datasets using functionality available in the Seurat3 package (50). Jointly clustering $w t I D H 1$ and $m I D H 1$ tumor-infiltrating immune cells showed that the granulocytic population formed three clusters corresponding to the $\mathrm{C} 1, \mathrm{C} 2$, and $\mathrm{C} 3$ clusters found in the $\mathrm{TME}$ of $m I D H 1$ tumors (Supplementary Fig. S9A). Interestingly, the majority of granulocytes from the TME of the wtIDH1 tumor clustered with $\mathrm{C} 1$ cluster of granulocytes from $m I D H 1$ tumors (Supplementary Fig. S9B, C), suggesting that these cells share a common origin and have a similar function. 
To further determine if $\mathrm{C} 1$ represents the true PMN-MDSCs within TME-mIDH1, we looked for a cell surface marker differentially expressed in $\mathrm{C} 1$ that would allow us to isolate cells from this cluster and assess their function. Among the top 50 differentially expressed genes in cluster $\mathrm{C} 1$, CD274 (PD-L1) was the only cell surface marker that showed high expression in C1 compared to moderate and low expression in C2 and C3, respectively (Fig. 3C; Supplementary Table S4). Based on CD274 expression, we reclassified the granulocytic populations of both TMEs. We found that there was one granulocyte population in the wtIDH1 tumor and three distinct granulocytic populations in the $m I D H 1$ tumor, corresponding to $\mathrm{C} 1, \mathrm{C} 2$, and $\mathrm{C} 3$ (Fig. 3D). We FACS sorted each population based on the expression of PD-L1 and determined their inhibitory potential by performing a T-cell proliferation assay. Similar to the results obtained with granulocytes from wtIDH1 TME (C7 cluster), co-culturing with $\mathrm{C} 1$ cells from $m I D H 1$ glioma results in $\sim 40 \%$ inhibition of T-cell proliferation $(\mathrm{p}<0.05)$, whereas $\mathrm{C} 2$ and $\mathrm{C} 3$ from $m I D H 1$ TME did not inhibit T-cell proliferation (Fig. 3E). These results validate the inhibitory potential of $\mathrm{C} 1$ as the true PMN-MDSCs cluster in $m I D H 1$ glioma TME.

\section{CD16/32 is a specific marker that defines immunosuppressive PMN-MDSCs in mice}

Our next goal was to identify a specific myeloid biomarker that would allow us to distinguish the inhibitory PMN-MDSCs from the non-inhibitory granulocytes. To identify a unique marker, we used a myeloid-specific antibody panel (Supplementary Table S1) that measures 30 myeloidspecific parameters simultaneously and used it to perform CYTOF analysis of the granulocytic clusters found in $m I D H 1$ and $w t I D H 1$ glioma TME. We found that granulocytes from wtIDH1 and the $\mathrm{C} 1$ cluster from $m I D H 1$ TME have similar expression of the majority of the myeloid biomarkers, with the FC-gamma receptor family (CD16/32) upregulated in all inhibitory PMNMDSCs (Fig. 3F). CD16/32 is expressed on macrophages and granulocytes, and its expression is 
correlated with maturation and function $(62,63)$. To confirm the correlation between PMNMDSCs phenotype and CD16/32 expression, we performed unsupervised clustering and dimensionality reduction which showed that granulocytes from $m I D H 1$ TME clustered differently than granulocytes from the wtIDH1 TME (Fig. 3G, H). We observed high CD16/32 expression exclusively in all granulocytes from wtIDH1 and only in $\mathrm{C} 1$ from $m I D H 1$ tumors (Fig. 3G, H). The majority of granulocytes from wtIDH1 TME ( 90\%) express high levels of CD16/32, while only $\sim 12 \%$ of granulocytes form $m I D H 1$ have high expression of CD16/32, the majority of which belongs to cluster $\mathrm{C} 1$ ( $\mathrm{p}<0.05$, Fig. 3G-I). This suggests that CD16/32 is a unique myeloid marker for immune-suppressive PMN-MDSCs in mice.

\section{PMN-MDSC gene signature is expressed in a higher proportion of tumor-infiltrating immune cells in human wtIDH1 glioma}

We then performed scRNA-seq of immune cells isolated from primary tumor samples of patients with wtIDH1 and $m I D H 1$ glioma. We collected 18 tumor samples from a total of 7 patients (8 samples from $w t I D H 1$ tumors, 10 samples from $m I D H 1$ tumors). After performing immune cell purification and applying quality controls, a total of 9,765 cells from wtIDH1 tumors and 17,452 from $m I D H 1$ tumors were analyzed. All patients' clinical data are listed in Supplementary Table S5. wtIDH1 and $m I D H 1$ datasets were analyzed separately using Seurat to reproduce cell type labels (Fig. 4A-D). Myeloid clusters were the most abundant immune cells infiltrating both the wtIDH1 and $m I D H 1$ human gliomas (Fig. 4A-D). In wtIDH1 tumors, there was a total of 5 clusters of myeloid cells (Myeloid C1-C5) (Fig. 4A, C); all of which expressed the granulocyte colony-stimulating factor receptor, a receptor that labels cells from granulocytic lineages $(C S F 3 R)$ (Supp Fig. S9D). Only one cluster (C4) expressed high microglial genes (C1Qc, AIF1) (Fig. 4A, C). In the $m I D H 1$ tumor, there were 4 clusters expressing CSF3R (Supp Fig. S9E). 
Similar to the mouse data, the largest cluster (Myeloid-C1) expressed CCL3, and CCL4 (Fig. 4B, D). Myeloid cluster C2 (Myeloid-C2) expressed antigen presentation-like genes (HLA-A and $H L A-D R A)$, whereas Myeloid-C3 expressed granulocytes differentiation genes (CSF3R, NEAT1; Fig. 4D). C4 cluster express the microglia-like genes $(C 1 Q B, C 1 Q C)$. We then investigated the expression of the PMN-MDSCs gene signature (IL1 $\beta, S 100 a 8, S 100 a 9, A R G 1, T G F \beta 1)$ within each cluster in $w t I D H 1$ and $m I D H 1$ myeloid cells, separately (Fig. 5A, B). In wtIDH1 tumors, Myeloid-C1 expressed high score for the PMN-MDSCs gene signature, whereas in the $m I D H 1$ group, myeloid-C5 expressed the highest score of PMN-MDSCs signature (Fig. 5A, B, Supp Fig. S9D, E). Nearly $17 \%$ of all immune cells in wtIDH1 tumors were PMN-MDSCs, whereas in the mIDH1 glioma TME, PMN-MDSCs were only $2.5 \%$ of the total immune cells (Fig. 5C). These results are consistent with our preclinical model data which showed that PMN-MDSCs are present at higher fraction in the TME of $w t I D H 1$ glioma than in the TME of $m I D H 1$ glioma.

\section{G-CSF is the major cytokine that is epigenetically regulated in mIDH1 glioma}

Our data demonstrate that the majority of the granulocytes found in $m I D H 1$ TME are noninhibitory granulocytes. We hypothesized that the change in granulocytes' phenotype and function is due to epigenetic reprogramming which affects cytokines' expression in the $m I D H 1$ glioma cells. Therefore, we profiled cytokines known to influence myeloid differentiation in conditioned media (CM) collected from wtIDH1, or mIDH1 cultured mouse glioma neurospheres. The expression of the majority of the cytokines was downregulated in CM from the $m I D H 1$ group compared to CM from $w t I D H 1$ (Fig. 6A ; Supplementary Fig. S10). GM-CSF, CXCL1, CXCL10, IL-5, MIP-2, IL-6, and TNF- $\alpha$ were among the downregulated cytokines in mIDH1 CM (Fig. 6A; Supplementary Fig. S10). However, G-CSF, RNATES (CCL5), IL-33, and SCF were the only cytokines that were upregulated in $m I D H 1 \mathrm{CM}$ (Supplementary Fig. S10). To 
investigate if these cytokines were epigenetically regulated by $m I D H 1$, we used a ChIP-seq dataset that we have recently reported (NCBI's Omnibus identifier: GSE99806), which was obtained using SB- generated neurospheres from $m I D H 1$ and wtIDH1 glioma (64). Gene promoters enriched for $\mathrm{H} 3 \mathrm{~K} 4 \mathrm{me} 3$ peaks are generally associated with transcriptional activation. Among the genes encoding the cytokines that were upregulated in CM from $m I D H 1$, only CSF3 showed a dramatic change in the peak enrichment for $\mathrm{H} 3 \mathrm{~K} 4 \mathrm{me} 3$ mark around the promoter region (Fig. 6B). Moreover, quantitative ELISA confirmed that the level of G-CSF was increased in $m I D H 1$ compared to $w t I D H 1$ in both the mouse serum of tumor-bearing animals, as well as in $\mathrm{CM}$ from cultured mouse and human neurospheres ( 5-fold, $\mathrm{P}<0.05$, Fig. $6 \mathrm{C}-\mathrm{E})$. In addition, TCGA-LGG analysis revealed that CSF3 gene expression level was significantly upregulate in mIDH1 glioma patients harboring $A T R X$ and TP53 mutation as compare to wtIDH1-LGG patients (Figure 6F). The increased level of G-CSF in $m I D H 1$ could explain the significant expansion of granulocytes in $m I D H 1$ tumor-bearing mice as well as the enrichment of the cytokine signaling pathway triggered by G-CSF receptor expressed on myeloid cells.

To uncover the source of G-CSF within gliomas, we performed scRNA-seq of whole tumors ( 5000 cells) isolated from SB induced $m I D H 1$ glioma model. Results show that the majority of G-CSF was expressed by the major tumor cell clusters, which belong to stem-like cells and express genes such as sox2, sox4, tcf4 (Fig. 6G, H). These results indicate that the undifferentiated tumor cells established by the developing $m I D H 1$ tumor express high levels of G-CSF, resulting in the phenotypic remodeling of the granulocytic population to nonimmunosuppressive neutrophils.

\section{G-CSF neutralization restores the immunosuppressive properties of $\mathrm{CD}^{\mathrm{high}} / \mathrm{CD}^{\mathrm{h}} \mathrm{b}^{+} / \mathrm{Ly}^{\mathrm{G}} \mathrm{G}^{+}$in $\mathrm{mIDH} 1 \mathrm{TME}$}


If the $\mathrm{CD} 45^{\text {high }} / \mathrm{CD} 11 \mathrm{~b}^{+} / \mathrm{Ly} 6 \mathrm{G}^{+}$phenotype in $m I D H 1$ is dependent on G-CSF expression, blocking G-CSF should reverse their immune-permissive phenotype. We depleted G-CSF in the $m I D H 1$ tumor-bearing animals using the $\alpha \mathrm{G}-\mathrm{CSF}$ neutralizing antibody (Fig. 7A). Treatment with $\alpha \mathrm{G}-\mathrm{CSF}$ significantly reduced the serum levels of G-CSF in $m I D H 1$ tumor-bearing mice $(\sim 86 \%$ and $\sim 92 \%$ decrease in day $14 \mathrm{dpi}$ and $21 \mathrm{dpi}$, respectively; $\mathrm{p}<0.01)$ and decreased the frequency of granulocytes in the TME, spleen, and BM $(\sim 40 \%, \sim 63 \%$, and $\sim 10 \%$, respectively, $\mathrm{p}$ $<0.05$ Fig. 7B, C). Interestingly, G-CSF neutralization remodeled the CD $45^{\text {high }} / \mathrm{CD} 11 \mathrm{~b}^{+} / \mathrm{Ly} 6 \mathrm{G}^{+}$ compartment within the TME of $m I D H 1$ tumor-bearing animals to an inhibitory phenotype, which results in $\sim 35 \%$ inhibition of $\mathrm{T}$-cell proliferation (Fig. 7D). Moreover, G-CSF neutralization shortened the MS of $m I D H 1$ (but not the wtIDH1) tumor-bearing animals (MS = 30dpi vs. MS $=18$ dpi; $\mathrm{p}<0.05$, in control vs. $\alpha$-GCSF, respectively, Fig. 7E). This demonstrates that the non-inhibitory properties of granulocytes in the $m I D H 1$ glioma bearing mice is driven by high expression of G-CSF.

CSF3 expression is associated with favorable outcome only in LGG patients harboring mIDH1

Tumor-derived G-CSF has been shown to promote tumor progression and enhanced metastasis in several tumor types $(65,66)$. To evaluate the effect of G-CSF in LGG patients, we turned to the TCGA data and analyzed the median survival (MS) of all tumor types available in the context of G-CSF (CSF3) expression (i.e. MS of patients expressing high vs low levels of CSF3). We used the UCSC-Xena browser to identify the differences in survival between patients with high or low levels of CSF3 expression. Interestingly, we found that LGG was the only tumor type in which a significant difference existed between the MS of patients with high vs low CSF3 expression (Supplementary Fig. S11). Moreover, when we stratified the astrocytoma patients according to 
$m I D H 1$ and $C S F 3$ expression, we found that enhanced median survival related to high $C S F 3$ expression was solely observed in patients with $m I D H 1$ tumors (Fig. 7F). There were no significant differences in MS between high vs low expression of other cytokines responsible for PMN-MDSCs development such as CSF1, IL4, IL1 $\beta$, TNF, IL6 in $m I D H 1$ patients (data not shown). These results suggest the unique correlation between G-CSF expression in $m I D H 1$ LGG patients and its impact on patients' survival.

\section{Glioma derived G-CSF induces the expansion of neutrophils and prolongs survival in mice}

To uncover if G-CSF alone is sufficient to induce the expansion of non-immunosuppressive neutrophils, we dosed wtIDH1 tumor-bearing mice with recombinant G-CSF (rG-CSF) (Fig. 7G). We used $2 \mu \mathrm{g}$ /day of rG-CSF to achieve steady-state serum G-CSF concentrations comparable to levels observed in $\mathrm{mIDH} 1$ tumor-bearing mice (Fig. 7B), and similar to reported doses $(67,68)$. Compared to vehicle-treated animals, wtIDH1 tumor-bearing animals treated with rG-CSF showed expansion of granulocytes in the TME (Fig. 7H). These granulocytes expressed lower levels of CD16/32 and PD-L1 compared to granulocytes from vehicle-treated control (Fig. 7I, J). Interestingly, rG-CSF administration remodeled granulocytes to non-inhibitory phenotype and significantly prolonged the MS of tumor-bearing animals (MS $=47 \mathrm{dpi}$ vs. $\mathrm{MS}=24 \mathrm{dpi}$; $<<0.05$, in rGCSF vs. control, respectively, Fig. 7K, L). These results supported the hypothesis that GCSF leads to the expansion of non-immune suppressive neutrophils and confirmed the association between the increased G-CSF secretion and enhanced prognosis in glioma. To validate the source of G-CSF, wtIDH1 neurospheres were stably transduced with lentivirus encoding G-CSF (lenti-GCSF) or with an empty lentivirus vector (lenti-vector). Sucessfully ransduced neurospheres were cultured in vitro for 14 days before they were used for implantation (Supp Fig S12). The enhanced G-CSF expression was confirmed by RT-qPCR as well as by ELISA in CM of cultured 
neurospheres (Supplementary Fig. S12B, C). As expected, results showed that animals implanted with wtIDH1-lenti-G-CSF neurospheres had increased $\mathrm{CD} 45^{\mathrm{high}} / \mathrm{CD} 11 \mathrm{~b}^{+} / \mathrm{Ly}_{6 \mathrm{G}}{ }^{+}$in the tumor, spleen, and BM compared to mice implanted with wtIDH1-Lenti-vector neurospheres (Supplementary Fig. S12D-F). Collectively, this data demonstrates the effect of tumor-derived GCSF on the phenotype and function of granulocytes in $m I D H 1$ glioma. 


\section{DISCUSSION}

A salient feature of $m I D H 1$ gliomas is the epigenetic modifications of the tumor cells' transcriptome mediated by inhibition of the methylcytosine dioxygenase TET2, and $\alpha \mathrm{KG}$ dependent histone demethylases. This results in a genome-wide hypermethylation phenotype and enhanced survival $(69,70)$. Our data shows that $m I D H 1$ stem-like glioma cells, through epigenetic modification, exhibit enhanced G-CSF expression, a strong inducer of myeloid cell development, proliferation, and mobilization (71-73). Enhanced G-CSF expression triggers a shift in myelopoiesis favoring the production of non-immunosuppressive granulocytes that infiltrate the $m I D H 1$ glioma TME. Thus, our study provides evidence of a novel mechanism that contributes to the enhanced median survival in $m I D H 1$ glioma.

Gliomas are characterized by a profound immunosuppressive milieu that is responsible, at least in part, for hindering the efficacy of immunotherapies (22-24). Previous studies have shown that glioblastoma patients have elevated levels of circulating MDSCs; the majority of which ( $\sim 82 \%)$ belong to PMN-MDSCs, and are associated with poor prognosis $(29,74,75)$. We have recently shown that the PMN-MDSCs are the predominant immunosuppressive myeloid cells which upon depletion, significantly enhanced the efficacy of immunotherapy and prolonged median survival in wtIDH1 glioma-bearing mice (25). These results highlight the immunosuppressive nature of wtIDH1 glioma infiltrating PMN-MDSCs. The exact phenotypic, molecular, and functional 
characterization of MDSCs in $m I D H 1$ glioma has not been revealed yet. An algorithm defining the true immunosuppressive MDSCs based on phenotypic, biochemical, and functional characteristics has been recently proposed (42). In our GEMM, although $m I D H 1$ tumor-bearing animals have a higher expansion of $\mathrm{CD} 45^{\mathrm{high}} / \mathrm{CD} 11 \mathrm{~b}^{+} / \mathrm{Ly}_{6 \mathrm{G}}{ }^{+}$cells, transcriptome and phenotypic analysis revealed that they lack the characteristic immune-suppressive gene signature of bona fide PMN-MDSCs $(41,42)$.

The exact mechanisms that control the switch between the suppressive vs. non-suppressive phenotype of polymorphonuclear myeloid cells remain unknown. One proposed mechanism is that two signals orchestrate the development of immunosuppressive myeloid cells (76). The first signal is responsible for the recruitment and proliferation of myeloid cells, i.e., GM-CSF, SCF, or G-CSF $(76,77)$. The second signal belongs to inflammatory cytokines such as IL-1 $\beta$, IL-6, TGF- $\beta$, or IL-4 that trigger an inflammatory milieu responsible for the development of the immune-suppressive properties of the tumor-infiltrating myeloid cells $(23,43,78)$. In line with this hypothesis, our data show that a cytokine belonging to the first signal (G-CSF) was epigenetically upregulated in $m I D H 1$ glioma bearing mice, whilst, all inflammatory cytokines responsible for the induction of MDSCs immunosuppression properties we tested were downregulated in $m I D H 1$ glioma. In addition, we found that G-CSF was expressed at a higher level in CM collected from cultured human glioma cells expressing mIDH/ATRX and TP53 inactivating mutations, when compared to CM collected from wtIDH1 glioma cells. Moreover, TCGA analysis revealed that the expression of CSF3 was higher in astrocytoma patients harboring $m I D H 1$ along with inactivation mutations in TP53, ATRX as compared to wtIDH1. Overall, our data demonstrated that $m I D H 1$ gliomas exhibited enhanced expression of CSF3. 
It has been recently shown that gliomas are highly heterogeneous tumors, having both intertumor and intra-tumor heterogeneity at the cellular and genomic levels (79-84). The mechanism by which genetic heterogeneity influences the tumor immune microenvironment remains elusive (85-88). The use of scRNA-seq technologies has now provided additional granularity which enables to chart subtypes of glioma immune cellular infiltrates within the glioma microenvironment. This technology enabled us to identify the developmental hierarchies within the glioma infiltrating myelopoietic cell clusters, uncovering novel drivers, and revealing the infiltrating-immune surveillance/evasion cell types relevant to tumors with specific genetic lesions $(84,89-91)$. We thus performed scRNA-seq of the tumor-infiltrating CD $45^{+}$immune cells harvested from our glioma GEMMs; both wtIDH1 and $m I D H 1$. Transcriptome profiling at the single cell level uncovered the global landscape of glioma-infiltrating myeloid cells and captured their heterogeneity. We discovered that the mIDH1 glioma-infiltrating granulocytes are comprised of three distinct cell clusters; $\mathrm{C} 1, \mathrm{C} 2$, and $\mathrm{C} 3$. We performed differential gene expression analysis between the three clusters and identified that cluster $\mathrm{C} 1$ was enriched in immunosuppressive PMN-MDSCs signature marker genes such as $t g f b, I l 1 b$, and Arg2. Cluster C2 expressed S100a8, ccl3, ccl4, and cell cycle genes such as Cdc20, G0s2 indicating proliferating neutrophils (pre-neutrophils). Whereas C3 expressed neutrophils maturation genes such as cebpe, and mpo. In contrast, in the wtIDHI glioma model, the tumor-infiltrating granulocytes are comprised of one single cluster expressing genes similar to granulocyte cluster, $\mathrm{C} 1$ in the $m I D H 1$ group.

Since a hallmark of MDSCs, is their inhibition of antigen specific $\mathrm{CD} 8^{+} \mathrm{T}$ cell proliferation, we 
next aimed to isolate the three newly identified granulocytic clusters encountered within the mIDH1 TME for functional characterization. An ideal marker would be expressed on the cell surface, and have different expression levels between the three clusters. Interrogation of the differentially expressed genes between $\mathrm{C} 1, \mathrm{C} 2$, and $\mathrm{C} 3$ revealed that CD274 (PD-L1) was expressed at a high level in PMN-MDSCs (cluster C1); compared to intermediate and low levels in the pre-neutrophils (cluster C2) and neutrophils (cluster C3), respectively (Fig. 3C). This allowed us to isolate each cluster and examine their T-cell inhibitory potential. Using this approach, we found that in the $m I D H 1$ group, cells in cluster $\mathrm{C} 1$ were suppressive whereas the cluster $\mathrm{C} 2$ and $\mathrm{C} 3$ were non-immunosuppressive, whereas in the wtIDH1 group, granulocytes expressing PD-L1 formed one single cluster of cells (C7), which inhibited $\mathrm{CD}^{+}{ }^{\mathrm{T}}$-cell proliferation. Finally, we performed in-depth high-dimensional mass cytometry characterization and phenotypic analysis of the three granulocytic clusters found in the mIDHI TME. An advantage of this approach is that automated clustering is done on data reduced to two tSNE dimensions, which allows visual verification of cluster boundaries at the single-cell resolution. Combined clustering of granulocytes infiltrating the TME of $m I D H 1$ or wtIDH1 GEMMs of glioma revealed that the majority of granulocytes from the wtIDHI tumor were allocated along with the $\mathrm{C} 1$ cluster of the $m I D H 1$ group. Cytof analysis also led to the identification of CD16/32 as a unique, and reproducible myeloid marker that can be used to distinguish immunosuppressive PMN-MDSCs from non-immunosuppressive granulocytes.

Consistent with results from our GEMMs of glioma, we found that the majority of immune cells infiltrating human gliomas expressing $m I D H 1$, exhibit a characteristic myeloid cell's gene signatures; all of which express the early granulocytic receptor G-CSFR. Interestingly, the 
largest myeloid cluster in the $m I D H 1$ glioma group expressed genes (CCL3, CCL4) similar to cluster $\mathrm{C} 2$ in our $m I D H 1$ GEMM of glioma. Moreover, using a unique PMN-MDSCs gene signature, our data elucidated that human $m I D H 1$ gliomas exhibit a lower frequency of tumorinfiltrating bona fide PMN-MDSCs when compared to the wtIDH1 glioma patients. Therefore, the molecular and phenotypic features of $m I D H 1$ on tumor-infiltrating PMN-MDSCs is largely conserved between our mouse model and human samples.

G-CSF was upregulated in the CM of cultured human and mouse mIDH1 NS. This increase was also significant in the serum from $m I D H 1$ tumor-bearing mice. We demonstrated that the increased G-CSF expression in $m I D H 1$ NS was due to epigenetic reprogramming of the tumor cells' transcriptome, in which the CSF3 gene showed an enrichment in the deposition of the H3K4me3 mark around the promoter region. We demonstrated that in our mIDH1 GEMM of glioma, tumor cells express a higher level of Sox2 and are less differentiated (46); consistent with earlier reports indicated that $I D H 1^{R 132 H}$ suppresses cellular differentiation $(92,93)$. scRNA-seq revealed that glioma stem-like cells that express Sox2 and Sox4 are the major source of G-CSF expression in $m I D H 1$ tumors. Therefore, the enhanced production of G-CSF is due to the presence of a higher proportion of less differentiated tumor cells in $m I D H 1$ glioma. In line with this, studies showed that within the glioma niche, glioma stem-like cells are found to be coenriched with myeloid infiltrating immune cells $(94,95)$.

The impact of G-CSF on tumor biology is still a point of debate. Recombinant G-CSF (Filgastim ${ }^{\circledR}$ ) is a commercially available product indicated for chemo-induced neutropenia to reverse myelosuppression in cancer patients and it has been shown to reduce inflammation and reverse cognitive impairment in patients with Alzheimer (96,97). In addition, increased G-CSF 
secretion has been implicated in the recruitment and infiltration of immunosuppressive MDSCs in breast cancer (65) and cervical cancer (66). In contrast, in mice bearing MCA203 sarcomas, G-CSF induced $\mathrm{CD} 11 \mathrm{~b}^{+} / \mathrm{Gr}-1^{\text {hi }}$ cells that were non-suppressive (98). It has also been shown that the administration of G-CSF leads to the formation of non-immunosuppressive

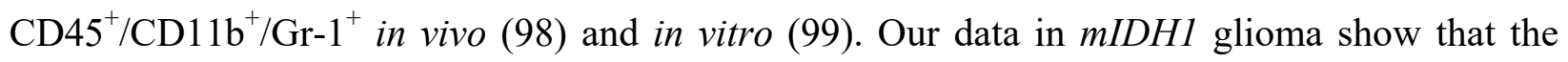
increased production of G-CSF by $m I D H 1$ glioma stem-like cells caused the expansion of $\mathrm{CD} 45^{\text {high }} / \mathrm{CD} 11 \mathrm{~b}^{+} / \mathrm{Ly}_{6 \mathrm{G}}^{+}$cells that exhibit a non-immunosuppressive phenotype. We also showed that rG-CSF administration to mice harboring wtIDH1 glioma reversed the immunosuppressive properties of the PMN-MDSCs, leading to increased median survival, similar to the median survival observed for $m I D H 1$ glioma bearing mice.

In summary, our data demonstrate that $m I D H 1$ tumor-derived G-CSF reprograms myelopoiesis in glioma, which promotes the production of non-immunosuppressive granulocytes, a feature that can be harnessed to enhance the immunotherapeutic efficacy in $m I D H 1$ glioma patients (Supplementary Fig S13). 


\section{ACKNOWLEDGEMENTS}

We greatly thank Kait Verbal, and Andrea Gunawan for all the help. We thank the support and academic leadership of Dr. Karin Muraszko, and the administrative and technical support of Angela Collada, and Marta Edwards, respectively. The content is solely the responsibility of the authors. 


\section{REFERENCES}

1. Ceccarelli M, Barthel FP, Malta TM, Sabedot TS, Salama SR, Murray BA, et al. Molecular Profiling Reveals Biologically Discrete Subsets and Pathways of Progression in Diffuse Glioma. Cell 2016;164(3):550-63 doi 10.1016/j.cell.2015.12.028.

2. Yan H, Parsons DW, Jin G, McLendon R, Rasheed BA, Yuan W, et al. IDH1 and IDH2 Mutations in Gliomas. New England Journal of Medicine 2009;360(8):765-73 doi 10.1056/NEJMoa0808710.

3. Figueroa ME, Abdel-Wahab O, Lu C, Ward PS, Patel J, Shih A, et al. Leukemic IDH1 and IDH2 Mutations Result in a Hypermethylation Phenotype, Disrupt TET2 Function, and Impair Hematopoietic Differentiation. Cancer cell 2010;18(6):553-67 doi 10.1016/j.ccr.2010.11.015.

4. Turcan S, Rohle D, Goenka A, Walsh LA, Fang F, Yilmaz E, et al. IDH1 mutation is sufficient to establish the glioma hypermethylator phenotype. Nature 2012;483(7390):479-83 doi 10.1038/nature10866.

5. Lu C, Ward PS, Kapoor GS, Rohle D, Turcan S, Abdel-Wahab O, et al. IDH mutation impairs histone demethylation and results in a block to cell differentiation. Nature 2012;483(7390):4748 doi 10.1038/nature10860.

6. Turcan S, Rohle D, Goenka A, Walsh LA, Fang F, Yilmaz E, et al. IDH1 mutation is sufficient to establish the glioma hypermethylator phenotype. Nature 2012;483(7390):479-83 doi 10.1038/nature10866.

7. Ward PS, Patel J, Wise DR, Abdel-Wahab O, Bennett BD, Coller HA, et al. The common feature of leukemia-associated IDH1 and IDH2 mutations is a neomorphic enzyme activity converting alpha-ketoglutarate to 2-hydroxyglutarate. Cancer cell 2010;17(3):225-34 doi 10.1016/j.ccr.2010.01.020.

8. Figueroa ME, Abdel-Wahab O, Lu C, Ward PS, Patel J, Shih A, et al. Leukemic IDH1 and IDH2 mutations result in a hypermethylation phenotype, disrupt TET2 function, and impair hematopoietic differentiation. Cancer cell 2010;18(6):553-67 doi 10.1016/j.ccr.2010.11.015.

9. Izquierdo-Garcia JL, Viswanath $\mathrm{P}$, Eriksson $\mathrm{P}$, Chaumeil MM, Pieper RO, Phillips JJ, et al. Metabolic reprogramming in mutant IDH1 glioma cells. PloS one 2015;10(2):e0118781 doi 10.1371/journal.pone.0118781.

10. Karpel-Massler G, Ishida CT, Bianchetti E, Zhang Y, Shu C, Tsujiuchi T, et al. Induction of synthetic lethality in IDH1-mutated gliomas through inhibition of $\mathrm{Bcl}-\mathrm{xL}$. Nature communications 2017;8(1):1067 doi 10.1038/s41467-017-00984-9.

11. Ronnebaum SM, Ilkayeva O, Burgess SC, Joseph JW, Lu D, Stevens RD, et al. A pyruvate cycling pathway involving cytosolic NADP-dependent isocitrate dehydrogenase regulates glucosestimulated insulin secretion. The Journal of biological chemistry 2006;281(41):30593-602 doi 10.1074/jbc.M511908200.

12. Seltzer MJ, Bennett BD, Joshi AD, Gao P, Thomas AG, Ferraris DV, et al. Inhibition of glutaminase preferentially slows growth of glioma cells with mutant IDH1. Cancer research 2010;70(22):8981-7 doi 10.1158/0008-5472.CAN-10-1666.

13. Dang L, White DW, Gross S, Bennett BD, Bittinger MA, Driggers EM, et al. Cancer-associated IDH1 mutations produce 2-hydroxyglutarate. Nature 2009;462(7274):739-44 doi 10.1038/nature08617.

14. Reitman ZJ, Duncan CG, Poteet E, Winters A, Yan LJ, Gooden DM, et al. Cancer-associated isocitrate dehydrogenase 1 (IDH1) $\mathrm{R} 132 \mathrm{H}$ mutation and d-2-hydroxyglutarate stimulate glutamine metabolism under hypoxia. The Journal of biological chemistry 2014;289(34):2331828 doi 10.1074/jbc.M114.575183. 
15. Yalaza C, Ak H, Cagli MS, Ozgiray E, Atay S, Aydin HH. R132H Mutation in IDH1 Gene is Associated with Increased Tumor HIF1-Alpha and Serum VEGF Levels in Primary Glioblastoma Multiforme. Ann Clin Lab Sci 2017;47(3):362-4.

16. Seok J, Yoon SH, Lee SH, Jung JH, Lee YM. The oncometabolite d2hydroxyglutarate induces angiogenic activity through the vascular endothelial growth factor receptor 2 signaling pathway. Int J Oncol 2019;54(2):753-63 doi 10.3892/ijo.2018.4649.

17. Zhao $S$, Lin $Y, X u$ W, Jiang $W$, Zha Z, Wang $P$, et al. Glioma-derived mutations in IDH1 dominantly inhibit IDH1 catalytic activity and induce HIF-1alpha. Science (New York, NY) 2009;324(5924):261-5 doi 10.1126/science.1170944.

18. Xu W, Yang H, Liu Y, Yang Y, Wang P, Kim SH, et al. Oncometabolite 2-hydroxyglutarate is a competitive inhibitor of alpha-ketoglutarate-dependent dioxygenases. Cancer cell 2011;19(1):17-30 doi 10.1016/j.ccr.2010.12.014.

19. Núñez FJ, Mendez FM, Kadiyala P, Alghamri MS, Savelieff MG, Garcia-Fabiani MB, et al. IDH1$\mathrm{R} 132 \mathrm{H}$ acts as a tumor suppressor in glioma via epigenetic up-regulation of the DNA damage response. Science translational medicine 2019;11(479):eaaq1427 doi 10.1126/scitranslmed.aaq1427.

20. Sampson JH, Gunn MD, Fecci PE, Ashley DM. Brain immunology and immunotherapy in brain tumours. Nature Reviews Cancer 2020;20(1):12-25 doi 10.1038/s41568-019-0224-7.

21. Reardon DA, Brandes AA, Omuro A, Mulholland P, Lim M, Wick A, et al. Effect of Nivolumab vs Bevacizumab in Patients With Recurrent Glioblastoma: The CheckMate 143 Phase 3 Randomized Clinical Trial. JAMA oncology 2020 doi 10.1001/jamaoncol.2020.1024.

22. Garcia-Fabiani MB, Ventosa M, Comba A, Candolfi M, Nicola Candia AJ, Alghamri MS, et al. Immunotherapy for gliomas: shedding light on progress in preclinical and clinical development. Expert Opin Investig Drugs 2020:1-26 doi 10.1080/13543784.2020.1768528.

23. Kamran N, Alghamri MS, Nunez FJ, Shah D, Asad AS, Candolfi M, et al. Current state and future prospects of immunotherapy for glioma. Immunotherapy 2018;10(4):317-39 doi 10.2217/imt2017-0122.

24. Altshuler DB, Kadiyala P, Nuñez FJ, Nuñez FM, Carney S, Alghamri MS, et al. Prospects of biological and synthetic pharmacotherapies for glioblastoma. Expert Opinion on Biological Therapy 2020;20(3):305-17 doi 10.1080/14712598.2020.1713085.

25. Kamran N, Kadiyala P, Saxena M, Candolfi M, Li Y, Moreno-Ayala MA, et al. Immunosuppressive Myeloid Cells' Blockade in the Glioma Microenvironment Enhances the Efficacy of ImmuneStimulatory Gene Therapy. Molecular therapy : the journal of the American Society of Gene Therapy 2017;25(1):232-48 doi 10.1016/j.ymthe.2016.10.003.

26. von Roemeling CA, Wang Y, Qie Y, Yuan H, Zhao H, Liu X, et al. Therapeutic modulation of phagocytosis in glioblastoma can activate both innate and adaptive antitumour immunity. Nature communications 2020;11(1):1508 doi 10.1038/s41467-020-15129-8.

27. Chang AL, Miska J, Wainwright DA, Dey M, Rivetta CV, Yu D, et al. CCL2 Produced by the Glioma Microenvironment Is Essential for the Recruitment of Regulatory T Cells and Myeloid-Derived Suppressor Cells. Cancer research 2016;76(19):5671-82 doi 10.1158/0008-5472.CAN-16-0144.

28. Raychaudhuri B, Rayman P, Huang P, Grabowski M, Hambardzumyan D, Finke JH, et al. Myeloid derived suppressor cell infiltration of murine and human gliomas is associated with reduction of tumor infiltrating lymphocytes. Journal of neuro-oncology 2015;122(2):293-301 doi 10.1007/s11060-015-1720-6.

29. Dubinski D, Wölfer J, Hasselblatt M, Schneider-Hohendorf T, Bogdahn U, Stummer W, et al. CD4+ T effector memory cell dysfunction is associated with the accumulation of granulocytic myeloid-derived suppressor cells in glioblastoma patients. Neuro-oncology 2015;18(6):807-18 doi 10.1093/neuonc/nov280. 
30. Gielen PR, Schulte BM, Kers-Rebel ED, Verrijp K, Petersen-Baltussen HMJM, ter Laan M, et al. Increase in Both CD14-Positive and CD15-Positive Myeloid-Derived Suppressor Cell Subpopulations in the Blood of Patients With Glioma But Predominance of CD15-Positive Myeloid-Derived Suppressor Cells in Glioma Tissue. Journal of Neuropathology \& Experimental Neurology 2015;74(5):390-400 doi 10.1097/NEN.0000000000000183.

31. Amankulor NM, Kim Y, Arora S, Kargl J, Szulzewsky F, Hanke M, et al. Mutant IDH1 regulates the tumor-associated immune system in gliomas. Genes \& development 2017;31(8):774-86 doi 10.1101/gad.294991.116.

32. Mu L, Long Y, Yang C, Jin L, Tao H, Ge H, et al. The IDH1 Mutation-Induced Oncometabolite, 2Hydroxyglutarate, May Affect DNA Methylation and Expression of PD-L1 in Gliomas. Frontiers in Molecular Neuroscience 2018;11(82) doi 10.3389/fnmol.2018.00082.

33. Berghoff AS, Kiesel B, Widhalm G, Wilhelm D, Rajky O, Kurscheid S, et al. Correlation of immune phenotype with IDH mutation in diffuse glioma. Neuro-oncology 2017;19(11):1460-8 doi 10.1093/neuonc/nox054.

34. Cimino PJ, Zager M, McFerrin L, Wirsching H-G, Bolouri H, Hentschel B, et al. Multidimensional scaling of diffuse gliomas: application to the 2016 World Health Organization classification system with prognostically relevant molecular subtype discovery. Acta neuropathologica communications 2017;5(1):39- doi 10.1186/s40478-017-0443-7.

35. Auezova R, Ivanova N, Akshulakov S, Zhetpisbaev B, Kozhakhmetova A, Ryskeldiyev N, et al. Isocitrate dehydrogenase 1 mutation is associated with reduced levels of inflammation in glioma patients. Cancer Manag Res 2019;11:3227-36 doi 10.2147/CMAR.S195754.

36. Chen Z, Feng X, Herting CJ, Garcia VA, Nie K, Pong WW, et al. Cellular and Molecular Identity of Tumor-Associated Macrophages in Glioblastoma. Cancer research 2017;77(9):2266 doi 10.1158/0008-5472.CAN-16-2310.

37. Chen Z, Hambardzumyan D. Immune Microenvironment in Glioblastoma Subtypes. Frontiers in Immunology 2018;9(1004) doi 10.3389/fimmu.2018.01004.

38. Louis DN, Perry A, Reifenberger G, von Deimling A, Figarella-Branger D, Cavenee WK, et al. The 2016 World Health Organization Classification of Tumors of the Central Nervous System: a summary. Acta neuropathologica 2016;131(6):803-20 doi 10.1007/s00401-016-1545-1.

39. Yvan-Charvet L, Ng LG. Granulopoiesis and Neutrophil Homeostasis: A Metabolic, Daily Balancing Act. Trends in immunology 2019;40(7):598-612 doi 10.1016/j.it.2019.05.004.

40. Németh T, Sperandio M, Mócsai A. Neutrophils as emerging therapeutic targets. Nature Reviews Drug Discovery 2020;19(4):253-75 doi 10.1038/s41573-019-0054-z.

41. Kumar V, Patel S, Tcyganov E, Gabrilovich DI. The Nature of Myeloid-Derived Suppressor Cells in the Tumor Microenvironment. Trends in immunology 2016;37(3):208-20 doi 10.1016/j.it.2016.01.004.

42. Bronte V, Brandau S, Chen SH, Colombo MP, Frey AB, Greten TF, et al. Recommendations for myeloid-derived suppressor cell nomenclature and characterization standards. Nature communications 2016;7:12150 doi 10.1038/ncomms12150.

43. Gabrilovich DI, Nagaraj S. Myeloid-derived suppressor cells as regulators of the immune system. Nature reviews Immunology 2009;9(3):162-74 doi 10.1038/nri2506.

44. Bronte V, Brandau S, Chen S-H, Colombo MP, Frey AB, Greten TF, et al. Recommendations for myeloid-derived suppressor cell nomenclature and characterization standards. Nat Commun 2016;7:12150- doi 10.1038/ncomms12150.

45. Veglia F, Perego M, Gabrilovich D. Myeloid-derived suppressor cells coming of age. Nature Immunology 2018;19(2):108-19 doi 10.1038/s41590-017-0022-x. 
46. Nunez FJ, Mendez FM, Kadiyala P, Alghamri MS, Savelieff MG, Garcia-Fabiani MB, et al. IDH1$\mathrm{R} 132 \mathrm{H}$ acts as a tumor suppressor in glioma via epigenetic up-regulation of the DNA damage response. Science translational medicine 2019;11(479) doi 10.1126/scitranslmed.aaq1427.

47. Calinescu A-A, Núñez FJ, Koschmann C, Kolb BL, Lowenstein PR, Castro MG. Transposon mediated integration of plasmid DNA into the subventricular zone of neonatal mice to generate novel models of glioblastoma. Journal of visualized experiments : JoVE 2015(96):10.3791/52443 doi 10.3791/52443.

48. Koschmann C, Calinescu A-A, Nunez FJ, Mackay A, Fazal-Salom J, Thomas D, et al. ATRX loss promotes tumor growth and impairs nonhomologous end joining DNA repair in glioma. Science translational medicine 2016;8(328):328ra28 doi 10.1126/scitranslmed.aac8228.

49. Alghamri MS, Núñez FJ, Kamran N, Carney S, Altshuler D, Lowenstein PR, et al. Chapter Six Functional characterization of tumor antigen-specific T-cells isolated from the tumor microenvironment of sleeping beauty induced murine glioma models. In: Galluzzi L, Rudqvist N$P$, editors. Methods in enzymology. Volume 631: Academic Press; 2020. p 91-106.

50. Stuart T, Butler A, Hoffman P, Hafemeister C, Papalexi E, Mauck WM, III, et al. Comprehensive Integration of Single-Cell Data. Cell 2019;177(7):1888-902.e21 doi 10.1016/j.cell.2019.05.031.

51. Butler A, Hoffman P, Smibert P, Papalexi E, Satija R. Integrating single-cell transcriptomic data across different conditions, technologies, and species. Nature biotechnology 2018;36(5):411-20 doi 10.1038/nbt.4096.

52. Koschmann C, Calinescu AA, Nunez FJ, Mackay A, Fazal-Salom J, Thomas D, et al. ATRX loss promotes tumor growth and impairs nonhomologous end joining DNA repair in glioma. Science translational medicine 2016;8(328):328ra28 doi 10.1126/scitranslmed.aac8228.

53. Calinescu AA, Nunez FJ, Koschmann C, Kolb BL, Lowenstein PR, Castro MG. Transposon mediated integration of plasmid DNA into the subventricular zone of neonatal mice to generate novel models of glioblastoma. Journal of visualized experiments : JoVE 2015(96) doi 10.3791/52443.

54. Amir el AD, Davis KL, Tadmor MD, Simonds EF, Levine JH, Bendall SC, et al. viSNE enables visualization of high dimensional single-cell data and reveals phenotypic heterogeneity of leukemia. Nature biotechnology 2013;31(6):545-52 doi 10.1038/nbt.2594.

55. Hambardzumyan D, Amankulor NM, Helmy KY, Becher OJ, Holland EC. Modeling Adult Gliomas Using RCAS/t-va Technology. Translational oncology 2009;2(2):89-95 doi 10.1593/tlo.09100.

56. Subramanian A, Tamayo P, Mootha VK, Mukherjee S, Ebert BL, Gillette MA, et al. Gene set enrichment analysis: a knowledge-based approach for interpreting genome-wide expression profiles. Proceedings of the National Academy of Sciences of the United States of America 2005;102(43):15545-50 doi 10.1073/pnas.0506580102.

57. Alghamri MS, Kamran N, Kadiyala P, Lowenstein PR, Castro MG. Chapter Twelve - Functional assay to assess T-cell inhibitory properties of myeloid derived suppressor cells (MDSCs) isolated from the tumor microenvironment of murine glioma models. In: Galluzzi L, Rudqvist N-P, editors. Methods in enzymology. Volume 632: Academic Press; 2020. p 215-28.

58. Tanay A, Regev A. Scaling single-cell genomics from phenomenology to mechanism. Nature 2017;541(7637):331-8 doi 10.1038/nature21350.

59. Gabrilovich DI. Myeloid-Derived Suppressor Cells. Cancer immunology research 2017;5(1):3-8 doi 10.1158/2326-6066.CIR-16-0297.

60. Alshetaiwi H, Pervolarakis N, McIntyre LL, Ma D, Nguyen Q, Rath JA, et al. Defining the emergence of myeloid-derived suppressor cells in breast cancer using single-cell transcriptomics. Science Immunology 2020;5(44):eaay6017 doi 10.1126/sciimmunol.aay6017.

61. Honey K. CCL3 and CCL4 actively recruit CD8+ T cells. Nature Reviews Immunology 2006;6(6):427- doi 10.1038/nri1862. 
62. Elghetany MT. Surface Antigen Changes during Normal Neutrophilic Development: A Critical Review. Blood Cells, Molecules, and Diseases 2002;28(2):260-74 doi https://doi.org/10.1006/bcmd.2002.0513.

63. Lambert C, Preijers FWMB, Yanikkaya Demirel G, Sack U. Monocytes and macrophages in flow: an ESCCA initiative on advanced analyses of monocyte lineage using flow cytometry. Cytometry Part B: Clinical Cytometry 2017;92(3):180-8 doi 10.1002/cyto.b.21280.

64. Nunez FJ, Mendez FM, Kadilaya P, Alghamri MS, Savelieff M, Koschmann C, et al. IDH1R132H acts as a tumor suppressor in glioma via epigenetic upregulation of the DNA damage response. bioRxiv 2018 doi 10.1101/389817.

65. Casbon AJ, Reynaud D, Park C, Khuc E, Gan DD, Schepers K, et al. Invasive breast cancer reprograms early myeloid differentiation in the bone marrow to generate immunosuppressive neutrophils. Proceedings of the National Academy of Sciences of the United States of America 2015;112(6):E566-75 doi 10.1073/pnas.1424927112.

66. Kawano M, Mabuchi S, Matsumoto $Y$, Sasano T, Takahashi R, Kuroda H, et al. The significance of G-CSF expression and myeloid-derived suppressor cells in the chemoresistance of uterine cervical cancer. Scientific reports 2015;5:18217 doi 10.1038/srep18217.

67. Meyer MA, Baer JM, Knolhoff BL, Nywening TM, Panni RZ, Su X, et al. Breast and pancreatic cancer interrupt IRF8-dependent dendritic cell development to overcome immune surveillance. Nature communications 2018;9(1):1250 doi 10.1038/s41467-018-03600-6.

68. Casbon A-J, Reynaud D, Park C, Khuc E, Gan DD, Schepers K, et al. Invasive breast cancer reprograms early myeloid differentiation in the bone marrow to generate immunosuppressive neutrophils. Proceedings of the National Academy of Sciences 2015;112(6):E566 doi 10.1073/pnas.1424927112.

69. Parsons DW, Jones S, Zhang X, Lin JC, Leary RJ, Angenendt P, et al. An integrated genomic analysis of human glioblastoma multiforme. Science (New York, NY) 2008;321(5897):1807-12 doi 10.1126/science.1164382.

70. Cancer Genome Atlas Research N, Brat DJ, Verhaak RG, Aldape KD, Yung WK, Salama SR, et al. Comprehensive, Integrative Genomic Analysis of Diffuse Lower-Grade Gliomas. The New England journal of medicine 2015;372(26):2481-98 doi 10.1056/NEJMoa1402121.

71. Wengner AM, Pitchford SC, Furze RC, Rankin SM. The coordinated action of G-CSF and ELR + CXC chemokines in neutrophil mobilization during acute inflammation. Blood 2008;111(1):42-9 doi 10.1182/blood-2007-07-099648.

72. Petit I, Szyper-Kravitz M, Nagler A, Lahav M, Peled A, Habler L, et al. G-CSF induces stem cell mobilization by decreasing bone marrow SDF-1 and up-regulating CXCR4. Nat Immunol 2002;3(7):687-94 doi 10.1038/ni813.

73. Knudsen E, Iversen PO, Boyum A, Seierstad T, Nicolaysen G, Benestad HB. G-CSF enhances the proliferation and mobilization, but not the maturation rate, of murine myeloid cells. Eur J Haematol 2011;87(4):302-11 doi 10.1111/j.1600-0609.2011.01658.x.

74. Raychaudhuri B, Rayman P, Ireland J, Ko J, Rini B, Borden EC, et al. Myeloid-derived suppressor cell accumulation and function in patients with newly diagnosed glioblastoma. Neuro-oncology 2011;13(6):591-9 doi 10.1093/neuonc/nor042.

75. Gan Y, Zhou X, Niu X, Li J, Wang T, Zhang H, et al. Neutrophil/Lymphocyte Ratio Is an Independent Prognostic Factor in Elderly Patients with High-Grade Gliomas. World neurosurgery 2019;127:e261-e7 doi https://doi.org/10.1016/i.wneu.2019.03.085.

76. Condamine T, Mastio J, Gabrilovich DI. Transcriptional regulation of myeloid-derived suppressor cells. Journal of leukocyte biology 2015;98(6):913-22 doi 10.1189/jlb.4RI0515-204R. 
77. Condamine T, Gabrilovich DI. Molecular mechanisms regulating myeloid-derived suppressor cell differentiation and function. Trends in immunology 2011;32(1):19-25 doi 10.1016/j.it.2010.10.002.

78. Serafini P, Borrello I, Bronte V. Myeloid suppressor cells in cancer: recruitment, phenotype, properties, and mechanisms of immune suppression. Semin Cancer Biol 2006;16(1):53-65 doi 10.1016/j.semcancer.2005.07.005.

79. Vartanian A, Singh SK, Agnihotri S, Jalali S, Burrell K, Aldape KD, et al. GBM's multifaceted landscape: highlighting regional and microenvironmental heterogeneity. Neuro-oncology 2014;16(9):1167-75 doi 10.1093/neuonc/nou035.

80. Inda M-D-M, Bonavia R, Seoane J. Glioblastoma multiforme: a look inside its heterogeneous nature. Cancers 2014;6(1):226-39 doi 10.3390/cancers6010226.

81. The Cancer Genome Atlas Research N, Chang K, Creighton CJ, Davis C, Donehower L, Drummond $\mathrm{J}$, et al. The Cancer Genome Atlas Pan-Cancer analysis project. Nature genetics 2013;45:1113 doi 10.1038/ng.2764.

82. Wang Q, Hu B, Hu X, Kim H, Squatrito M, Scarpace L, et al. Tumor Evolution of Glioma-Intrinsic Gene Expression Subtypes Associates with Immunological Changes in the Microenvironment. Cancer cell 2017;32(1):42-56 e6 doi 10.1016/j.ccell.2017.06.003.

83. Verhaak RG, Hoadley KA, Purdom E, Wang V, Qi Y, Wilkerson MD, et al. Integrated genomic analysis identifies clinically relevant subtypes of glioblastoma characterized by abnormalities in PDGFRA, IDH1, EGFR, and NF1. Cancer cell 2010;17(1):98-110 doi 10.1016/j.ccr.2009.12.020.

84. Neftel C, Laffy J, Filbin MG, Hara T, Shore ME, Rahme GJ, et al. An Integrative Model of Cellular States, Plasticity, and Genetics for Glioblastoma. Cell 2019;178(4):835-49.e21 doi https://doi.org/10.1016/i.cell.2019.06.024.

85. McLendon R, Friedman A, Bigner D, Van Meir EG, Brat DJ, M. Mastrogianakis G, et al. Comprehensive genomic characterization defines human glioblastoma genes and core pathways. Nature 2008;455(7216):1061-8 doi 10.1038/nature07385.

86. Ding L, Ley TJ, Larson DE, Miller CA, Koboldt DC, Welch JS, et al. Clonal evolution in relapsed acute myeloid leukaemia revealed by whole-genome sequencing. Nature 2012;481(7382):50610 doi 10.1038/nature10738.

87. Pombo Antunes AR, Scheyltjens I, Duerinck J, Neyns B, Movahedi K, Van Ginderachter JA. Understanding the glioblastoma immune microenvironment as basis for the development of new immunotherapeutic strategies. eLife 2020;9:e52176 doi 10.7554/eLife.52176.

88. Doucette T, Rao G, Rao A, Shen L, Aldape K, Wei J, et al. Immune Heterogeneity of Glioblastoma Subtypes: Extrapolation from the Cancer Genome Atlas. Cancer Immunology Research 2013;1(2):112 doi 10.1158/2326-6066.CIR-13-0028.

89. Venteicher AS, Tirosh I, Hebert C, Yizhak K, Neftel C, Filbin MG, et al. Decoupling genetics, lineages, and microenvironment in IDH-mutant gliomas by single-cell RNA-seq. Science (New York, NY) 2017;355(6332) doi 10.1126/science.aai8478.

90. Suvà ML, Tirosh I. The Glioma Stem Cell Model in the Era of Single-Cell Genomics. Cancer cell 2020;37(5):630-6 doi https://doi.org/10.1016/j.ccell.2020.04.001.

91. Patel AP, Tirosh I, Trombetta JJ, Shalek AK, Gillespie SM, Wakimoto H, et al. Single-cell RNA-seq highlights intratumoral heterogeneity in primary glioblastoma. Science (New York, NY) 2014;344(6190):1396-401 doi 10.1126/science.1254257.

92. Modrek AS, Golub D, Khan T, Bready D, Prado J, Bowman C, et al. Low-Grade Astrocytoma Mutations in IDH1, P53, and ATRX Cooperate to Block Differentiation of Human Neural Stem Cells via Repression of SOX2. Cell reports 2017;21(5):1267-80 doi 10.1016/j.celrep.2017.10.009. 
93. Lu C, Ward PS, Kapoor GS, Rohle D, Turcan S, Abdel-Wahab O, et al. IDH mutation impairs histone demethylation and results in a block to cell differentiation. Nature 2012;483(7390):4748 doi 10.1038/nature10860.

94. Otvos B, Silver DJ, Mulkearns-Hubert EE, Alvarado AG, Turaga SM, Sorensen MD, et al. Cancer Stem Cell-Secreted Macrophage Migration Inhibitory Factor Stimulates Myeloid Derived Suppressor Cell Function and Facilitates Glioblastoma Immune Evasion. STEM CELLS 2016;34(8):2026-39 doi 10.1002/stem.2393.

95. Ye X-Z, Xu S-I, Xin Y-h, Yu S-c, Ping Y-f, Chen L, et al. Tumor-Associated Microglia/Macrophages Enhance the Invasion of Glioma Stem-like Cells via TGF- $\beta 1$ Signaling Pathway. The Journal of Immunology 2012;189(1):444-53 doi 10.4049/jimmunol.1103248.

96. Sanchez-Ramos J, Song S, Sava V, Catlow B, Lin X, Mori T, et al. Granulocyte colony stimulating factor decreases brain amyloid burden and reverses cognitive impairment in Alzheimer's mice. Neuroscience 2009;163(1):55-72 doi https://doi.org/10.1016/j.neuroscience.2009.05.071.

97. Li B, Gonzalez-Toledo ME, Piao C-S, Gu A, Kelley RE, Zhao L-R. Stem cell factor and granulocyte colony-stimulating factor reduce $\beta$-amyloid deposits in the brains of APP/PS1 transgenic mice. Alzheimer's Research \& Therapy 2011;3(2):8 doi 10.1186/alzrt67.

98. Dolcetti L, Peranzoni E, Ugel S, Marigo I, Fernandez Gomez A, Mesa C, et al. Hierarchy of immunosuppressive strength among myeloid-derived suppressor cell subsets is determined by GM-CSF. Eur J Immunol 2010;40(1):22-35 doi 10.1002/eji.200939903.

99. Marigo I, Bosio E, Solito S, Mesa C, Fernandez A, Dolcetti L, et al. Tumor-induced tolerance and immune suppression depend on the C/EBPbeta transcription factor. Immunity 2010;32(6):790802 doi 10.1016/j.immuni.2010.05.010. 


\section{Figure Legends}

Figure 1. mIDH1 glioma model has the highest expansion of granulocytic myeloid cells $\left(\mathbf{C D}^{\text {high }} / \mathbf{C D 1 1 b}^{+} / \mathrm{Ly6G}^{+}\right)$. (A) Experimental design of sleeping beauty (SB)-based tumor development, immune cells isolation and CyTOF analysis. (B) Schematic representation illustrating the two groups of neurospheres generated with different genetic lesions using the SB model. (C, D) SPADE analysis of mass cytometry (CyTOF) data represents immune cell composition within the TME of SB induced wtIDH1 (C) or $m I D H 1$ (D) tumors. Insets are viSNE visualizations of high-dimensional mass cytometry data; color intensity represents the Gr-1 expression level. (E, F) After neurospheres implantation, myeloid-derived suppressor cells were identified as $\mathrm{CD} 45^{\text {high }} / \mathrm{CD} 11 \mathrm{~b}^{+} / \mathrm{Gr}-1^{+}$cells within the TME at mid-stage of tumor implantation and at symptomatic stage. The percentage of $\mathrm{CD} 45^{\text {high }} / \mathrm{CD} 11 \mathrm{~b}^{+} / \mathrm{Gr}-1^{+}$cells was the highest in mIDH1 tumors. (G) Phenotypic characterization of $\mathrm{CD} 45^{\text {high }} / \mathrm{CD} 11 \mathrm{~b}^{+} / \mathrm{Gr}-1^{+}$population into granulocytic or monocytic based on the expression of Ly6G or Ly6C at symptomatic stage. The majority of the $\mathrm{CD} 45^{\text {high }} / \mathrm{CD} 11 \mathrm{~b}^{+} / \mathrm{Gr}-1^{+}$in the $m I D H 1$ glioma TME are CD $45^{\text {high }} / \mathrm{CD} 11 \mathrm{~b}^{+} / \mathrm{Ly} 6 \mathrm{G}^{+}$ (granulocytic) cells. (H, I) CyTOF analysis of $\mathrm{CD} 45^{\text {high }} / \mathrm{CD} 11 \mathrm{~b}^{+} / \mathrm{Gr}-1^{+}$cells in blood from mice with no tumor (normal), and SB induced wtIDH1 or mIDH1 glioma. (J) Phenotypic characterization of circulating $\mathrm{CD} 45^{\mathrm{high}} / \mathrm{CD} 11 \mathrm{~b}^{+} / \mathrm{Gr}-1^{+}$cells according to expression of Ly6C or Ly6G. (K, L) CyTOF analysis of CD $45^{\text {high }} / \mathrm{CD} 11 \mathrm{~b}^{+} / \mathrm{Gr}-1^{+}$cells from the spleens of mice with no tumor, and SB induced wtIDHl or $m I D H 1$ glioma. (M) Phenotypic characterization of splenic $\mathrm{CD} 45^{\text {high }} / \mathrm{CD} 11 \mathrm{~b}^{+} / \mathrm{Gr}-1^{+}$cells according to expression of Ly6C or Ly6G. N: normal, $* P<0.05$, ** $P<0.01, * * * P<0.005, * * * * P<0.0001$. Analysis of variance (ANOVA). 


\section{Figure 2. Phenotypic, molecular and functional characterization of myeloid cells lineages in} mIDH1 glioma. (A) Representative flow cytometry plots showing the percentage of hematopoietic stem cells (HSCs) $\left(\mathrm{Lin}^{-} / \mathrm{c}-\mathrm{Kit}^{+} / \mathrm{Sca}-1^{+}\right)$and myeloid progenitors (MP) ( $\mathrm{Lin}^{-} / \mathrm{c}-\mathrm{Kit}^{-}$ $/ \mathrm{Sca}^{+} \mathrm{1}^{+}$) in BM from normal mice, and mice implanted with wtIDH1 or $\mathrm{mIDH1}$ neurospheres. (B, C) Quantification of the number and frequency of (B) HSCs and (C) MPs from the BM of naïve mouse, and tumor-bearing animals at symptomatic stage. Mice with $m I D H 1$ tumor have a lower number and frequency of HSCs but higher frequency of MPs. Flow cytometry analysis of the frequency of (D) Granulocyte-macrophage progenitors (GMPs) (Lin $/ \mathrm{IL}-7 \mathrm{R}^{-} / \mathrm{c}-\mathrm{kit}{ }^{+} / \mathrm{Sca}-1^{-}$ $/ \mathrm{CD} 34^{+} /$FcyRII$_{/ \mathrm{III}^{\text {high }}}$ ) and (E) Common lymphocyte progenitors (CLPs) (c-kit ${ }^{\text {low }} / \mathrm{Sca}-1^{\text {low }} / \mathrm{Lin}^{-}$ /IL-7R $\alpha^{+}$) in the BM from naïve and wtIDH1 or $m I D H 1$ tumor-bearing animals. $m I D H 1$ tumor had a higher frequency of GMPs but not CLPs in the BM compared to the wtIDH1 group. (F) Schematic diagram representing the shift in hematopoiesis towards granulocytic-lineage development in the bone marrow of $\mathrm{mIDH} 1$ tumor-bearing mice. Thick arrows represent predominant developmental pathways in $\mathrm{mIDH} 1$ tumor bearing mice. (G) Heat map showing the normalized expression of genes related to PMN-MDSCs immunosuppressive signature in granulocytes from $w t I D H 1$ or $m I D H 1$ TME. CD $45^{\text {high }} / \mathrm{CD} 11 b^{+} / \mathrm{Ly}_{6 \mathrm{G}}{ }^{+}$cells from $m I D H 1 \mathrm{TME}$ have lower expression of immune suppressive markers. (H-M) Flow cytometry analysis of immunosuppressive/co-stimulatory markers in the $\mathrm{CD} 45^{\mathrm{high}} / \mathrm{CD} 11 \mathrm{~b}^{+} / \mathrm{Ly} 6 \mathrm{G}^{+}$population within TME of wtIDH1 (black) or mIDH1 (blue) TME. Granulocytes from mIDH1 tumors have lower expression of all tested markers. (N) Schematic of the in vitro T-cell proliferation assay to analyze immune suppressive properties of $\mathrm{CD} 45^{\text {high }} / \mathrm{CD} 11 \mathrm{~b}^{+} / \mathrm{Ly}_{6 \mathrm{G}}{ }^{+}$cells.

$\mathrm{CD}_{4} 5^{\text {high }} / \mathrm{CD}_{11 \mathrm{~b}^{+}} / \mathrm{Ly}_{6 \mathrm{G}}{ }^{+}$cells were co-cultured with CFSE-labeled splenocytes from Rag2/OT-1 transgenic mouse. Cultures were stimulated with 100 nM SIINFEKL peptide for 4 days, after 
which proliferation was analyzed by flow cytometry (O) Representative flow plots showing CFSE staining of unstimulated splenocytes ( $\mathrm{T}$ only), splenocytes undergoing rapid proliferation in response to SIINFEKL (T+ SIIN), and the effect of SIINFEKL-induced T-cell proliferation in the presence of $\mathrm{CD} 45^{\text {high }} / \mathrm{CD} 11 \mathrm{~b}^{+} / \mathrm{Ly} 6 \mathrm{G}^{+}$cells from the TME of $w t I D H 1$ or $m I D H 1$ tumors. (P) Flow analysis of the inhibitory potential of $\mathrm{CD} 45^{\mathrm{high}} / \mathrm{CD} 11 \mathrm{~b}^{+} / \mathrm{Ly} 6 \mathrm{G}^{+}$cells from TME of $w t I D H 1$ or $m I D H 1$ tumor. $\mathrm{CD} 45^{\text {high }} / \mathrm{CD} 11 \mathrm{~b}^{+} / \mathrm{Ly}_{6 \mathrm{G}} \mathrm{G}^{+}$cells from TME-wtIDH1 tumors are immunosuppressive, whereas $\mathrm{CD} 45^{\text {high }} / \mathrm{CD} 11 \mathrm{~b}^{+} / \mathrm{Ly}_{6 \mathrm{G}}{ }^{+}$cells from TME of $m I D H 1$ tumors did not suppress T-cell proliferation. ${ }^{*} P<0.05$, $* * P<0.01$, $* * * P<0.005$, One-way ANOVA.

\section{Figure 3. Neutrophils and pre-neutrophils are the major granulocytes population in mIDH1}

tumors. (A) Schematic overview of single-cell-seq and mass cytometry (CyTOF) analysis of immune cells purified from TME of $\mathrm{SB} w t I D H 1$ and $m I D H 1$ tumor-bearing animals. (B) Combined Seurat analysis of immune cells from $m I D H 1$ shown in UMAP projection results in various distinct clusters of TME immune cells. Granulocytes were identified in three clusters in the mIDH1 TME (C1, C2, C3) (N=2) (C) Heatmap of differentially expressed immunosuppressive and neutrophil-related genes between the three granulocytic clusters of mIDH1 TME group. C1 has a high expression of immune suppressive genes, whereas C2 and C3 have lower expression. $\mathrm{C} 3$ has a high expression of characteristic neutrophil genes such as $M P O$, CEBPE, and ETS1. Arrow reperesent CD274 expression. (D) Mass cytometry analysis of granulocytes from TME of wtIDH1 (Top panel) or $m I D H 1$ (bottom panel) tumors. Based on PDL1 expression, granulocytes from wtIDH1 tumor clustered in one cell population whereas in mIDH1, PD-L1 (CD274) expression, separated the granulocytes into three clusters corresponding to clusters $\mathrm{C} 1, \mathrm{C} 2$, and $\mathrm{C} 3$ of the scRNA-seq data. (E) T-cell proliferation analysis to assess the 
inhibitory potential of myeloid cells cluster (C7) from wtIDH1 tumors or $\mathrm{C} 1, \mathrm{C} 2$, and $\mathrm{C} 3$ myeloid cells clusters isolated from mIDH1 tumors. C7 myeloid cells cluster from the TME of wtIDH1 tumors and $\mathrm{C} 1$ myeloid cells cluster from $m I D H 1$ tumor TME are immunosuppressive, whereas $\mathrm{C} 2$ and $\mathrm{C} 3$ from $m I D H 1$ TME did not suppress T-cell proliferation. (F) Heat map representing CyTOF normalized expression level of myeloid biomarkers within granulocytes from the TME of $w t I D H 1$ tumors or $\mathrm{C} 1, \mathrm{C} 2$, and $\mathrm{C} 3$ clusters from the TME of $m I D H 1 . \mathrm{CD} 16 / 32$ (arrow) is reproducibly expressed in immunosuppressive PMN-MDSCs. (G, H) Unsupervised clustering and viSNE visualization of granulocytes from $w t I D H 1$ (G) or $m I D H 1$ (H) tumors using biomarker shown in (F). Circumscribed area indicates PMN-MDSCs from wtIDH1, which expressed a high level of CD16/32. (I) Proportion of PMN-MDSCs (\% of total granulocytes) from TME of wtIDH1 or $m I D H 1$ TME. The majority of granulocytes from $w t I D H 1(\sim 90 \%)$ correspond to PMN-MDSCs, whereas only $12-16 \%$ of granulocytes from $m I D H 1$ belong to PMN-MDSCs. $* P<0.05, * * P<0.01$. Student's $t$-test

\section{Figure 4. Single-cell RNA-seq analysis of primary human gliomas expressing wtIDH1 or}

mIDH1. (A, B) Seurat analysis of immune cells from (A) $w t I D H 1$ or (B) $m I D H 1$ primary tumor samples shown in UMAP projection results in various distinct clusters. In total, there were five myeloid clusters in wtIDH1 tumors. The PMN-MDSCs cluster formed the major cell population in $w t I D H 1$ but not in the $m I D H 1$ group. (C) Heat map showing the differentially expressed genes in each cluster of $w t I D H 1$ tumor samples. (D) Heat map showing the differentially expressed genes in each cluster of the $m I D H 1$ tumor samples. 


\section{Figure 5. mIDH1 gliomas exhibit lower frequencies of tumor infiltrating PMN-MDSCs. (A)}

Bar plots showing the relative PMN-MDSCs score in each cluster of primary human samples from (A) $w t I D H 1$ or (B) $m I D H 1$ tumors. Cluster $\mathrm{C} 1$ in the $w t I D H 1$ and cluster $\mathrm{C} 5$ in the $m I D H 1$ exhibit the highest expression of PMN-MDSC gene signature. (F) Quantification of the percentage of tumor-infiltrating PMN-MDSCs/total immune cells calculated from scRNA-seq data in $w t I D H 1$ and $m I D H 1$ human gliomas.

Figure 6. G-CSF is the major epigenetically regulated cytokine expressed by glioma stem-

like cells. (A) Cytokine array analysis performed on conditioned media from $w t I D H 1$, or $m I D H 1$ neurospheres. Bar graphs show the pixel intensity of each spot. Dash boxes indicate the candidate cytokines that may contribute to the myeloid phenotypic change. (B) H3K4me3 occupancy at specific genomic regions of CSF3 gene. Reads were visualized using IGV, and differential peaks (FDR $<0.05)$ in $m I D H 1$ neurospheres are represented in red compared to wtIDH1 neurospheres in blue. (C-E) Quantitative ELISA of the G-CSF level in mouse serum of tumor-bearing animals (C), conditioned media from mouse neurospheres cultures (D), and conditioned media from human neurospheres cultures expressing $w I D H 1$ or $m I D H 1$ (E). (F) Analysis of CSF3 (G-CSF) gene expression for mIDH1 glioma patients harboring TP53 and ATRX mutation ( $\mathrm{n}=99$ ), and $w t I D H 1$ ( $\mathrm{n}=82)$. RNA-seq data was obtained from TCGA (Xena browser platform). Graph displays the $\log _{2}$ expression value of $C S F 3$ mRNA. (G, H) Combined Seurat analysis shown in tSNE projection of whole tumor cells from $m I D H 1$ GEMM of glioma results in various distinct clusters of tumor cells. The expression of CSF3 was analyzed between the clusters. Stem-like cells were the major clusters that have the highest CSF3 expression. $(\mathrm{N}=2) * P<0.05, * * P<0.01$, $* * * P<0.005$ 
Figure 7. G-CSF neutralization restores the immunosuppressive potential of $\mathrm{CD}^{\mathrm{high}} / \mathrm{CD}^{\mathrm{C}} \mathrm{b}^{+} / \mathrm{Ly6G}^{+}$cells in $\mathrm{mIDH1}$ glioma and shortened the MS of $\mathrm{mDH} 1$ tumorbearing mice. (A) Schematic showing experimental design of G-CSF neutralization in wtIDH1 and $m I D H 1$ tumor-bearing mice. (B) Quantitative ELISA analysis of G-CSF level from serum of mIDH1 glioma bearing mice treated with either isotype (red) or $\alpha \mathrm{G}-\mathrm{CSF}$ (blue). (C) Flow analysis of $\mathrm{CD} 45^{\mathrm{high}} / \mathrm{CD} 11 \mathrm{~b}^{+} / \mathrm{Ly}_{6 \mathrm{G}}{ }^{+}$cells from tumor, spleen, and $\mathrm{BM}$ of tumor-bearing mice treated with either isotype or $\alpha \mathrm{G}-\mathrm{CSF}$. G-CSF neutralization decreased the percentage of

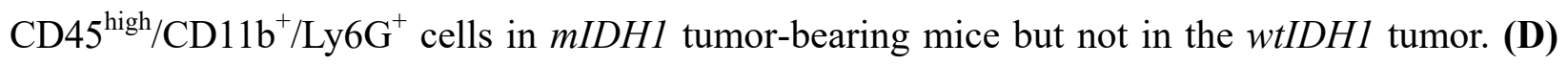
T-cell proliferation assay demonstrated that G-CSF neutralization restored the immune suppressive potential of $\mathrm{CD} 45^{\mathrm{high}} / \mathrm{CD} 11 \mathrm{~b}^{+} / \mathrm{Ly} 6 \mathrm{G}^{+}$in $m I D H 1$ tumor-bearing mice. (E) KaplanMeier survival analysis of mice implanted with either wtIDH1 or $m I D H 1$ neurospheres treated with isotype or $\alpha \mathrm{G}-\mathrm{CSF}$. Neutralization of G-CSF decreased the MS of $m I D H 1$ tumor-bearing mice, but it did not affect the MS of wtIDH1tumor bearing mice. (F) Kaplan-Meier survival analysis of TCGA-LGG astrocytoma $w t I D H 1$ or $m I D H 1$ patients with high vs low level of CSF3 expression. (G) Experimental design of recombinant G-CSF (rG-CSF) or vehicle administration in wtIDH1 tumor-bearing animals. (H) Flow analysis of granulocytes from the tumor of wtIDH1 tumor-bearing animals treated with vehicle or rG-CSF. (I, J) Flow analysis of CD16/32 and PDL1 expression on granulocytes isolated from wtIDH1 tumor-bearing animals treated with vehicle (blue) or rG-CSF (Red). (K) Flow analysis of the inhibitory potential of CD $45^{\text {high }} / \mathrm{CD} 11 \mathrm{~b}^{+} / \mathrm{Ly} 6 \mathrm{G}^{+}$ cells isolated from TME of wtIDH1 tumor-bearing mice treated with vehicle (blue) or with rG$\mathrm{CSF}$ (red). $\mathrm{CD} 45^{\text {high }} / \mathrm{CD} 11 \mathrm{~b}^{+} / \mathrm{Ly} 6 \mathrm{G}^{+}$cells from $\mathrm{TME}$ of $w t I D H 1+$ veh tumors are immunosuppressive, whereas $\mathrm{CD} 45^{\mathrm{high}} / \mathrm{CD} 11 \mathrm{~b}^{+} / \mathrm{Ly} 6 \mathrm{G}^{+}$cells from $\mathrm{TME}$ of $w t I D H 1+\mathrm{rG}-\mathrm{CSF}$ tumors did not suppress T-cell proliferation. (L) Kaplan-Meier survival analysis of animals 
bearing wtIDH1 tumors treated with either isotype (blue) or rG-CSF (red). rG-CSF treatment increased the MS of $w t I D H 1$ tumor-bearing animals $(w t I D H 1+$ iso $\mathrm{MS}=24 \mathrm{dpi}, w t I D H 1+\mathrm{rGCSF}$ $\mathrm{MS}=47$ dpi). $* P<0.05, * * P<0.01, * * * P<0.005$. ANOVA 


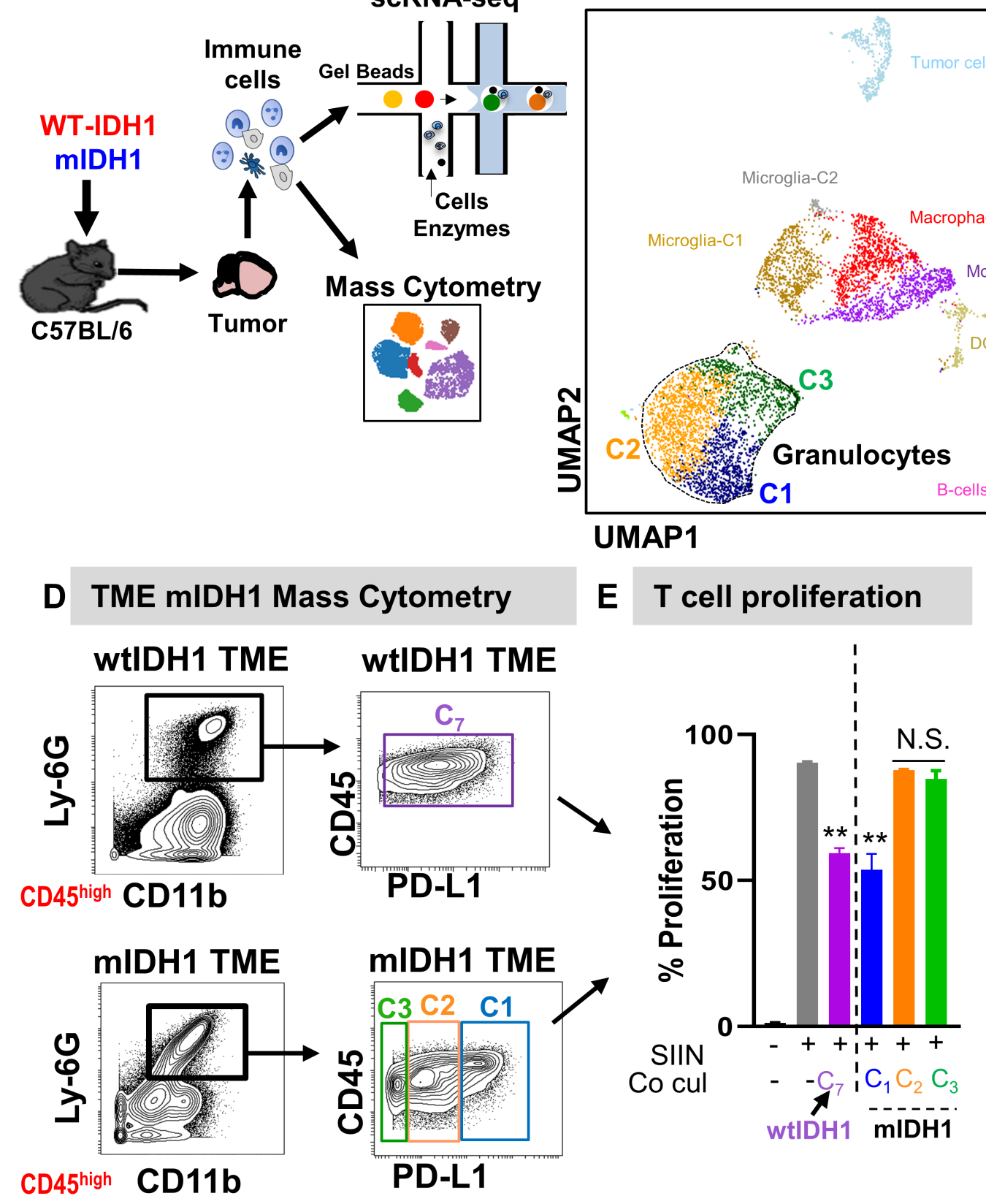

G

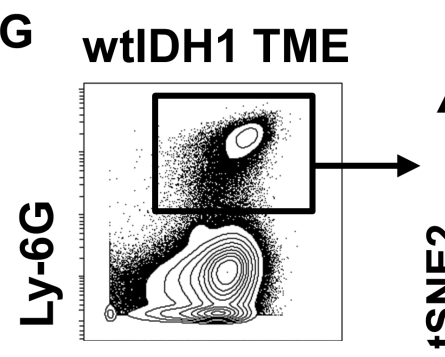

CD45 high CD11b

H

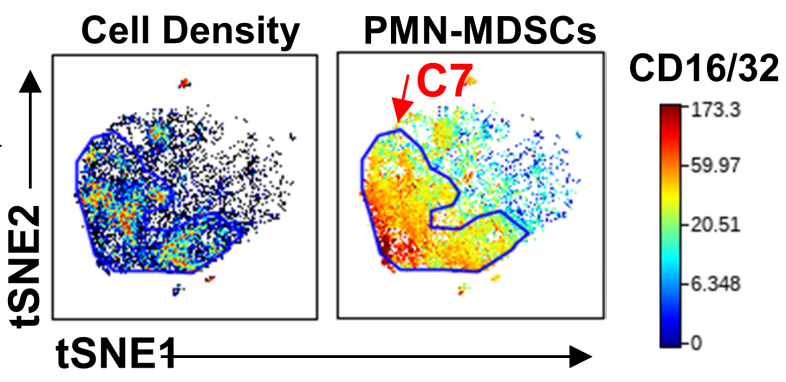

H mIDH1 TME

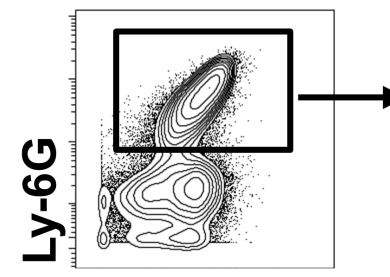

CD45 high CD11b

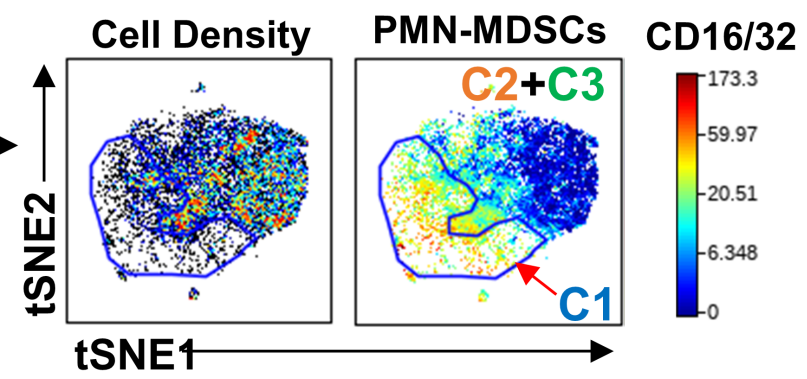

C1 C2 C3

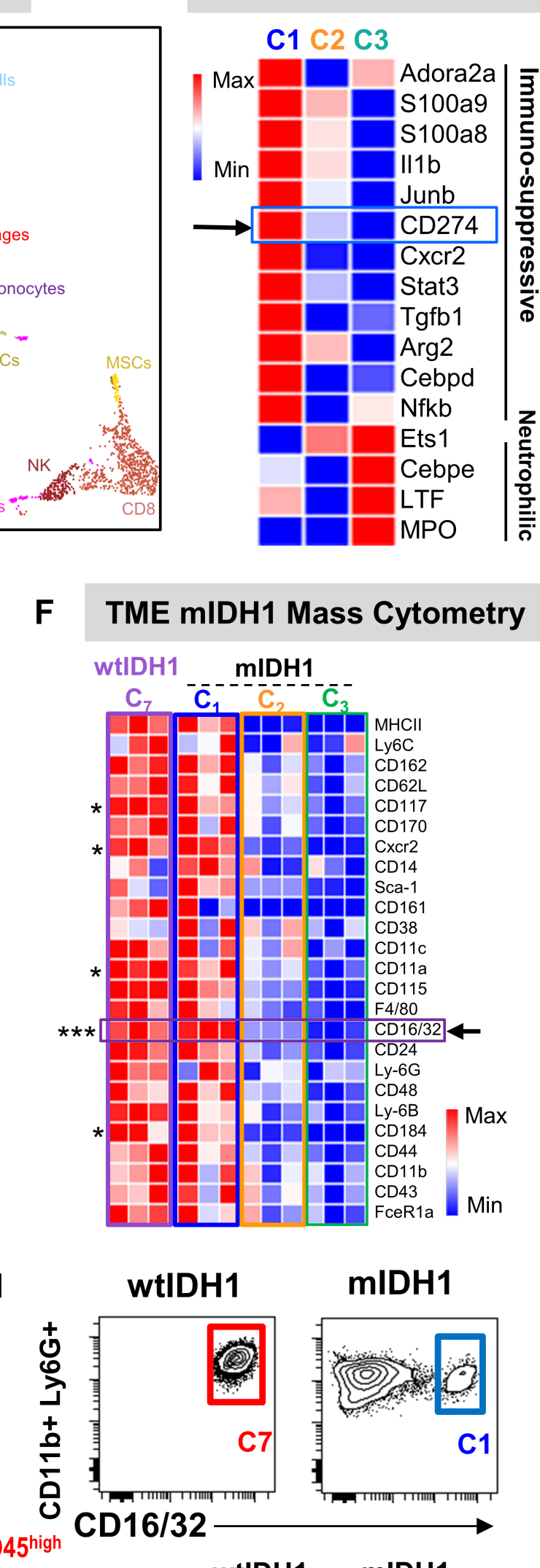

F TME mIDH1 Mass Cytometry

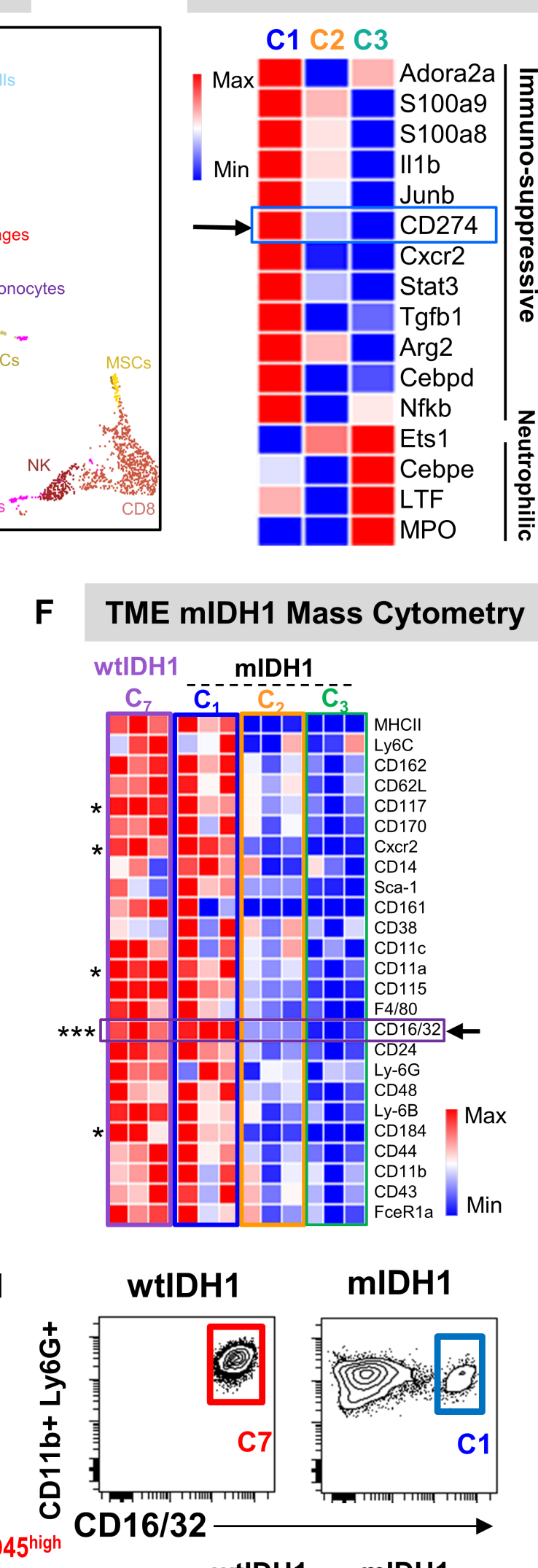

I

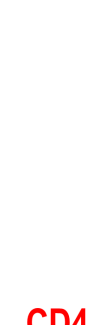

$\cos ^{\circ} 5^{\circ}$

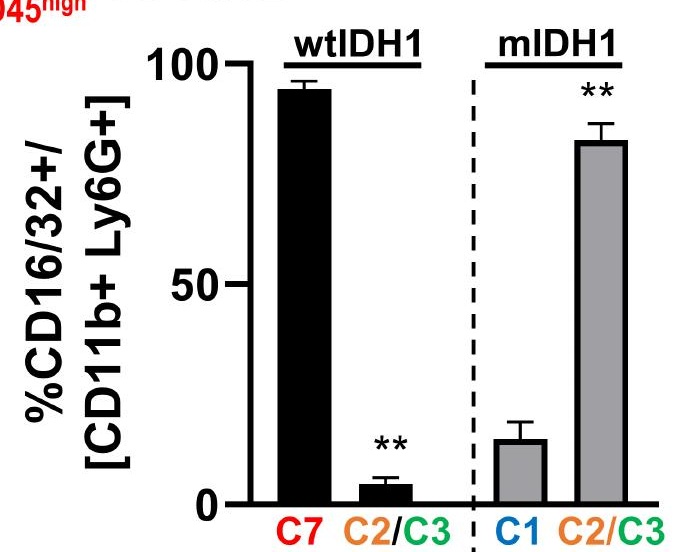


A
N
是
J

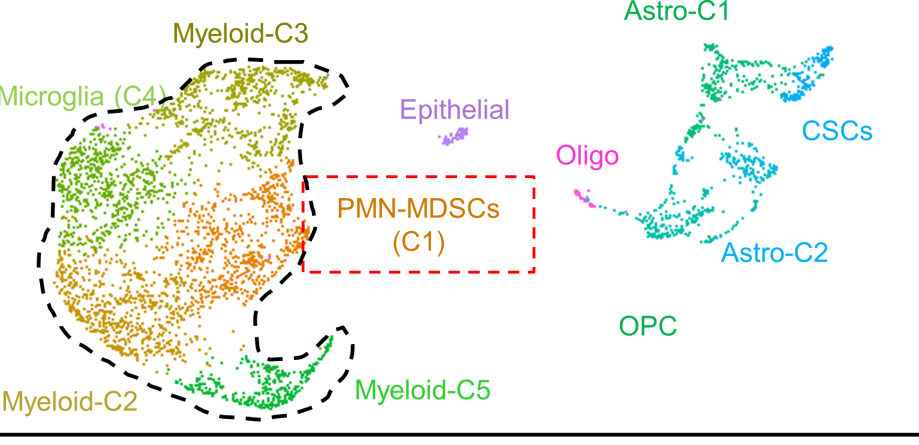

UMAP 1

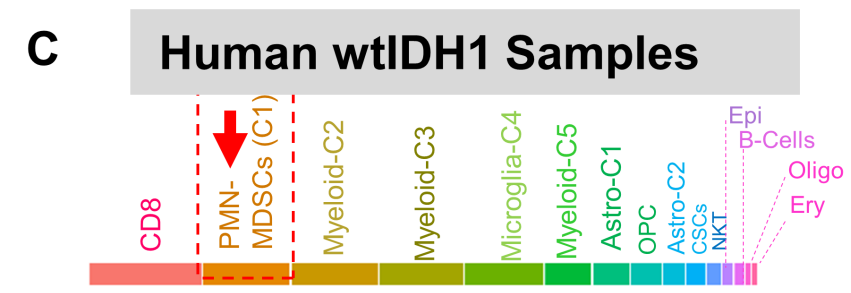

B Human mIDH1 Samples

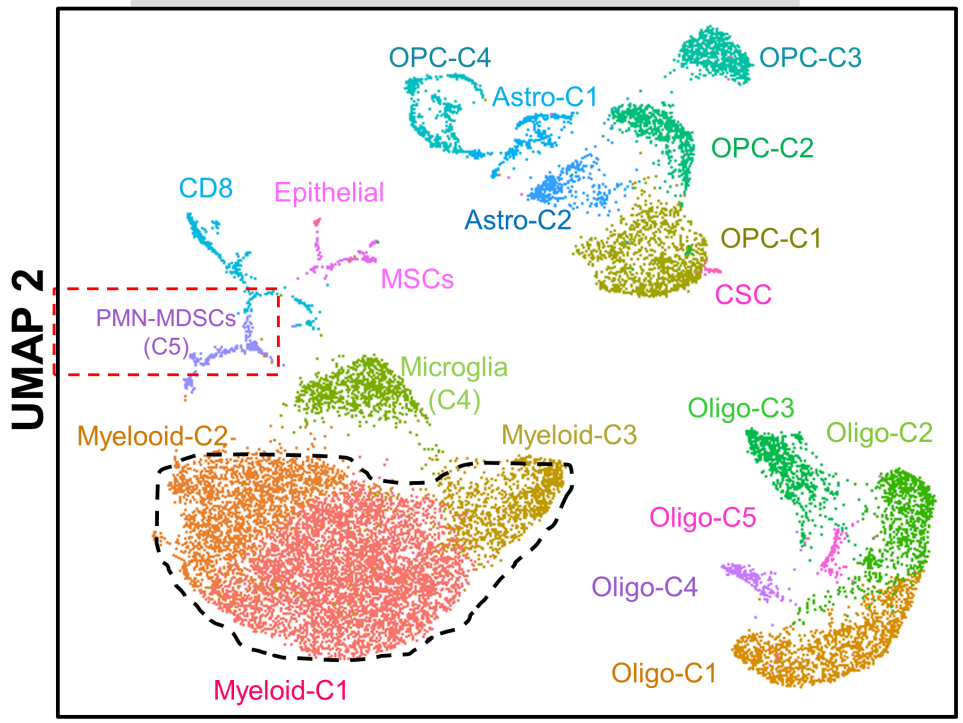

UMAP 1

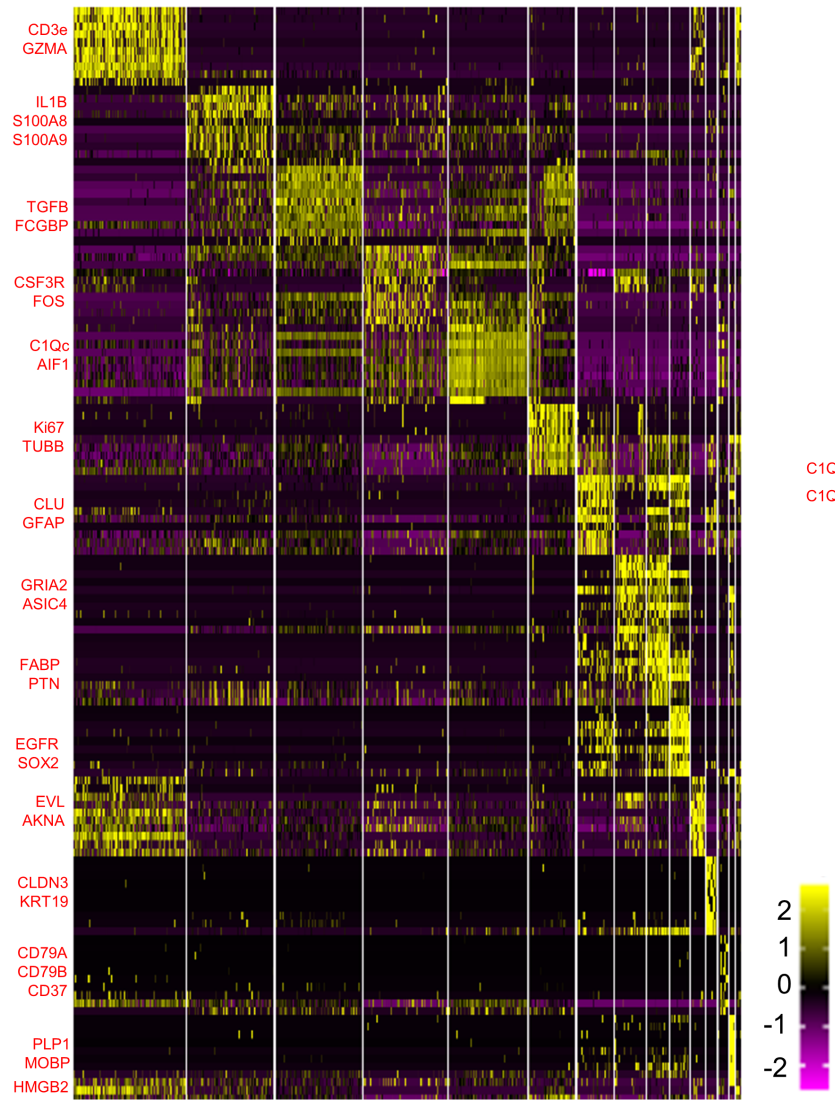

D Human mIDH1 Samples

Oligo-C4

MSCs

1 Oligo-C5 


\section{A Human wtIDH1 glioma}

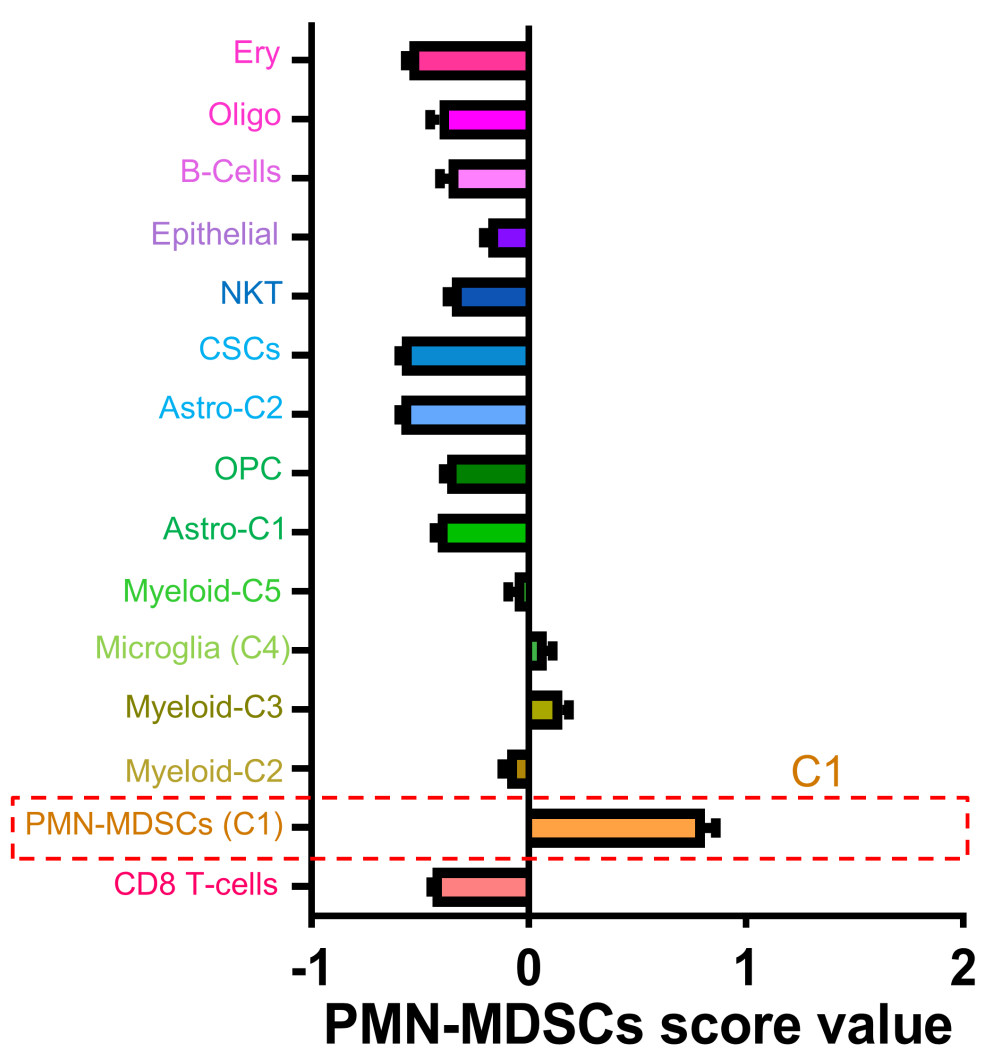

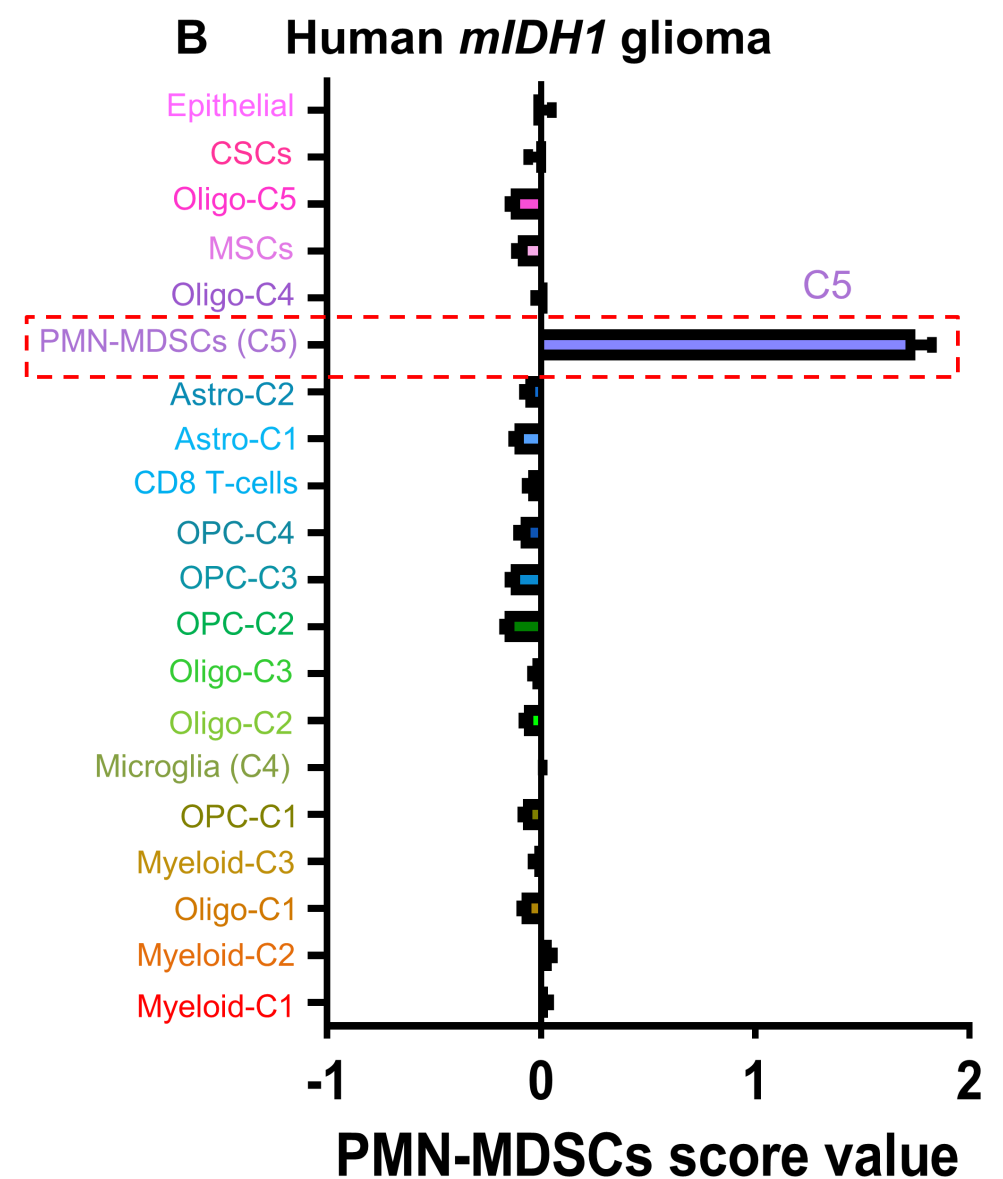

\section{Fraction of PMN-MDSCs}

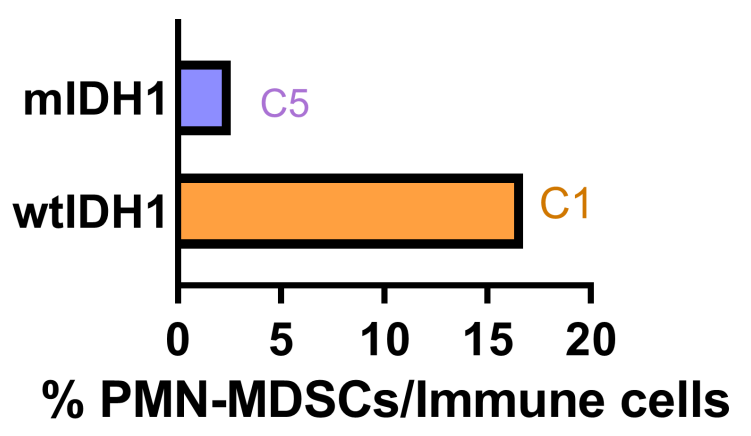




\section{A}

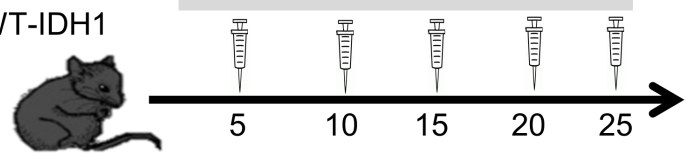

B

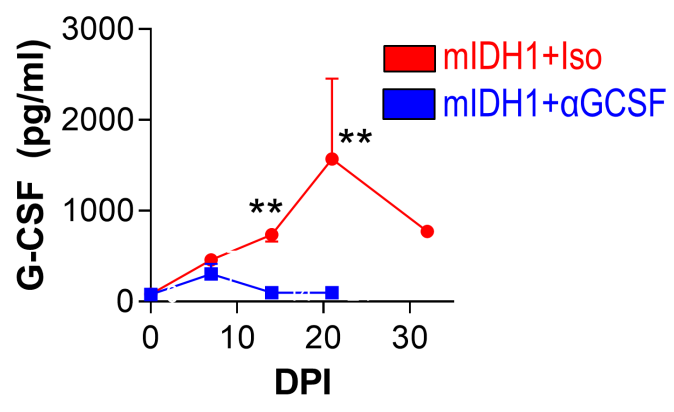

\section{T cell proliferation}

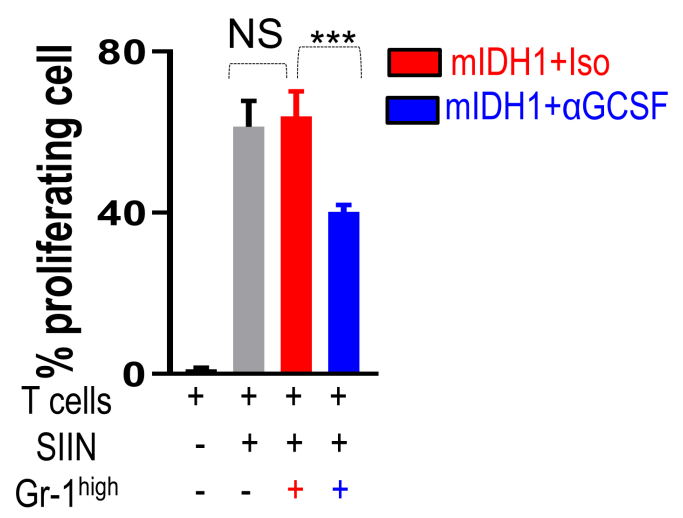

G
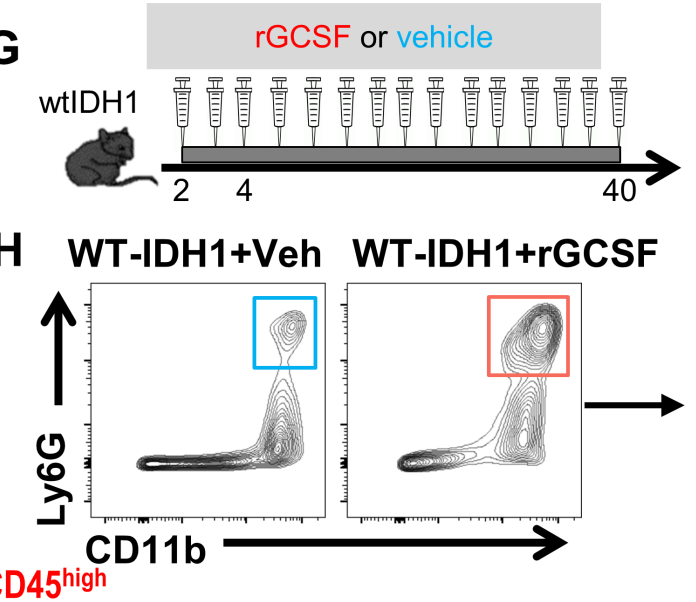

K

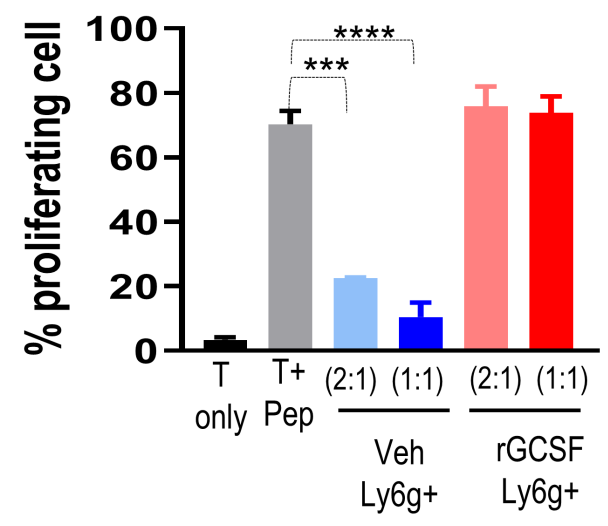

BM, Spleen, TME

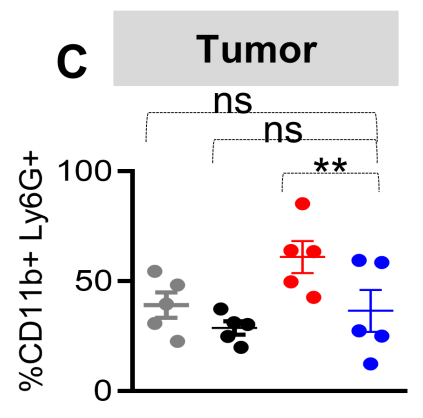

Spleen
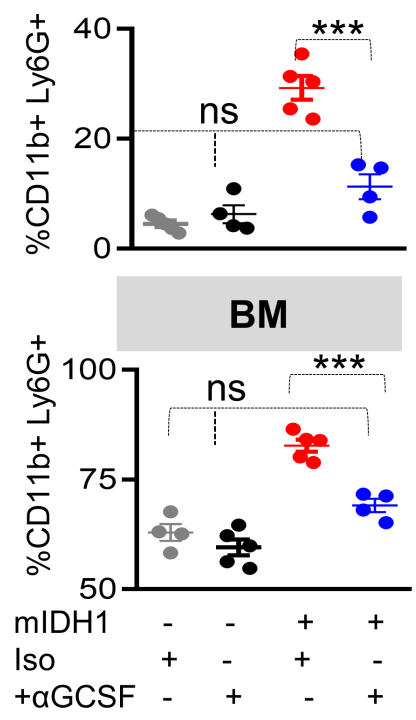

MDSCs characterization

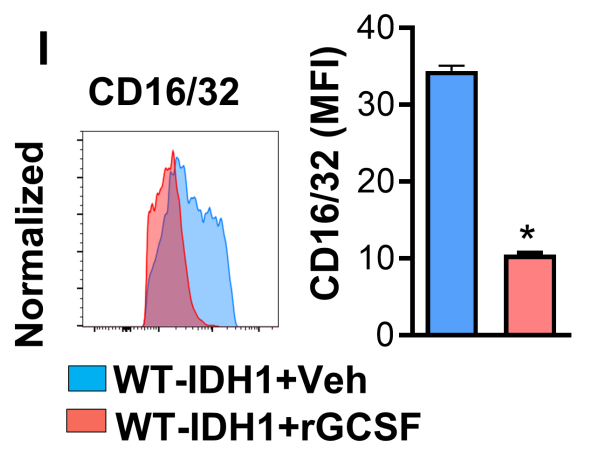

\section{F TCGA-LGG CSF3 expression}

\section{LGG-Astrocytoma}
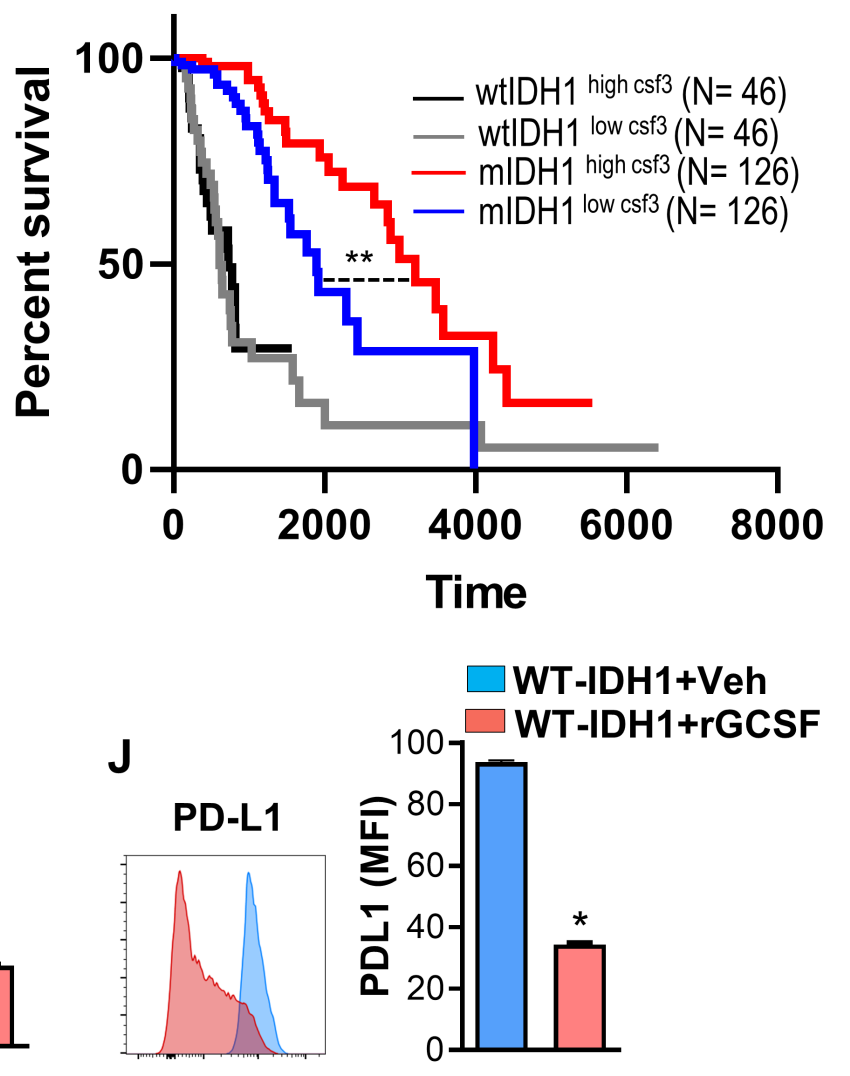